\title{
CERÁMICA Y CONTEXTOS DE TRÁNSITO EN LA RUTA CALAMA-QUILLAGUA, VÍA CHUG-CHUG, DESIERTO DE ATACAMA, NORTE DE CHILE
}

\author{
POTTERY AND STOPPING POINTS ALONG THE CALAMA-QUILLAGUA \\ ROUTE, VIA CHUG-CHUG, ATACAMA DESERT, NORTHERN CHILE
}

\author{
Itaci Correa ${ }^{1}$ y Magdalena García ${ }^{2}$
}

\begin{abstract}
La amplia distribución y abundancia de restos cerámicos asociados a la ruta prehispánica que comunicó el oasis de Quillagua con el oasis de Calama, cuenca del río Loa, indica que estos contenedores cumplieron un rol importante para los viajeros del pasado. La alta restaurabilidad de la fragmentería permitió desarrollar un estudio a nivel de vasijas semicompletas, entendiendo que su depositación en la ruta, intencional o accidental, constituye el momento final de una larga biografía. A través de análisis tipológicos, morfofuncionales y contextuales, así como la incorporación de documentación etnográfica y etnohistórica, concluimos que los contenedores cerámicos estudiados fueron utilizados para el servicio y almacenaje de bebidas y alimentos, principalmente en contextos ceremoniales que intentamos precisar. En términos cronológicos, los contextos cerámicos estudiados datan del periodo Intermedio Tardío (ca. 900-1.350 d.C.), evidenciando ocupaciones menos intensas en épocas previas y posteriores. Finalmente, constatamos un predominio indiscutible del componente alfarero Loa-San Pedro en todos los sitios, al que se agrega el componente Tarapacá y, en menor medida, tradiciones alfareras altiplánicas, del Noroeste Argentino y del Cuzco.
\end{abstract}

Palabras claves: cerámica prehispánica, vialidad, desierto de Atacama, ceremonialismo, análisis morfofuncional.

The wide distribution and large number of fragmented pottery along the Prehispanic route that connected the Quillagua and Calama oases in the Loa river basin show that these recipients played an important role for travelers in the past. The high frequency of vessel restorability allowed study of semi-complete vessels, with an understanding that their deposition along the route -whether intentionally or accidentally-constitutes only the final stage of a long life history. Through typological, morpho-functional, and contextual analyses, and the use of ethnographic and ethnohistorical documentation, we conclude that the ceramic recipients under study were used for food and beverage service and storage, mainly in ceremonial contexts that we attempt to define. Chronologically, the ceramic assemblages presented here date to the Late Intermediate Period (900-1,350 AD), suggesting previous and subsequent occupations were less intense in character. Finally, the Loa-San Pedro pottery tradition predominates at all the sites, accompanied by a Tarapacá component and, to a lesser extent, examples of Altiplano, Northwestern Argentinan and Cuzco ceramic traditions.

Keywords: Prehispanic pottery, mobility, Atacama Desert, ceremonialism, morpho-functional analysis.

Durante las últimas décadas han existido importantes avances en la identificación y registro de la compleja red de caminos que articuló el Área Centro Sur Andina en tiempos prehispánicos, abriendo un fecundo campo de investigación para la arqueología, sobre todo en el desierto de Atacama donde la preservación de esta clase de sitios es incomparable. Siguiendo a Berenguer (2004) y Núñez y Nielsen (2011), estas rutas representan una manifestación concreta de las prácticas vinculadas a la interacción social y la circulación de bienes y, en este sentido, constituyen una línea de evidencia novedosa para abordar problemáticas arqueológicas tradicionalmente tratadas desde la funebria y los contextos habitacionales.
El reciente interés por los caminos ha contribuido a enriquecer el viejo problema de la movilidad y el intercambio en los Andes, el cual tiene sus orígenes en el modelo de la Verticalidad de Murra (1975 [1972]). Éste, construido a partir de datos obtenidos de censos coloniales tempranos de Huanuco y Chucuito, daba cuenta de una estrategia económica y territorial mantenida por los Lupaqa, aparentemente desde tiempos prehispánicos. Dicha estrategia se caracterizaba por la mantención de terrenos productivos en espacios lejanos al lago Titicaca, en los valles cálidos de ambas vertientes andinas, desde donde se proveían de productos como maíz, ají y algodón, entre otros. Esta dinámica, basada en el acceso directo, habría conformado verdaderos

\footnotetext{
1 Programa de Doctorado en Arqueología, Facultad de Filosofía y Letras, Universidad de Buenos Aires. kusvetiver@gmail.com

2 Programa de Doctorado en Arqueología, Universidad Católica del Norte-Universidad de Tarapacá. San Pedro de AtacamaArica, Chile.manegarciab@yahoo.com
} 
archipiélagos territoriales y étnicos, articulados por un tráfico continuo entre el núcleo y sus islas periféricas, ubicadas en distintos pisos ecológicos (Murra 1975 [1972], 1976).

Posteriormente, un segundo modelo que tuvo gran impacto fue la Movilidad Giratoria (Núñez y Dillehay 1979), el cual ofreció una alternativa para los territorios del Área Centro Sur Andina, considerados en el primer modelo como "periféricos". Este puso especial énfasis en los vectores y rutas de movilidad, desplazando el foco de atención desde los centros habitacionales y funerarios hacia los espacios intermedios, que se visualizaban como "vacíos". El modelo, construido a partir de múltiples evidencias de arte rupestre, especialmente geoglifos, asociados a las rutas prehispánicas permitió dimensionar la importancia de la domesticación de la llama más allá de la producción de alimentos y textiles, destacando su capacidad de transporte en relación con un movimiento intensivo de poblaciones y objetos en el área (Núñez 1976). La Movilidad Giratoria se basó en la supuesta existencia de asentamientos-ejes emplazados en distintos pisos ecológicos y articulados por medio del excedente generado por cada comunidad, el cual era movilizado a partir del tráfico de caravanas generando una dinámica que en última instancia no sólo motivó el intercambio económico, sino también la interacción social, cultural y religiosa (Núñez y Dillehay 1979).

Con el avance de las investigaciones se han elaborado exámenes detallados de estos modelos, destacando sus virtudes y falencias, y proponiendo enfoques más flexibles en consonancia con la variabilidad cultural que caracteriza a lo andino y, en especial, posicionando las relaciones humanas por sobre lo ecológico (Angelo 2006; Berenguer 2004; Lazzari 2005; Martínez 1998; Nielsen 2006; Salomon 1985; Uribe 2006, Van Buren 1996). Con ello, estos "espacios vacíos" se han ido llenando de contenido, a partir del registro de una gran diversidad de sitios vinculados al tránsito, como: recintos de descanso, paskanas, simples parapetos o aprovechamiento de abrigos rocosos; estructuras en U destinadas a facilitar el manejo de los cargueros; corrales; geoglifos y petroglifos; estructuras ceremoniales; y enclaves temporales de tarea (Berenguer 2004; Nielsen 1997, 2011; Núñez y Nielsen 2011; Pimentel 2009).

Basándose en estos antecedentes, el objetivo del presente trabajo es estudiar la fragmentería cerámica asociada a la ruta Quillagua-Calama, la cual atraviesa un extenso espacio hiperdesértico aún poco conocido para la arqueología surandina aunque de enorme relevancia patrimonial, al concentrar el mayor número de geoglifos de la región de Antofagasta (Briones y Castellón 2005; Núñez 1976; Pimentel 2011a). Junto con ello, la ruta se asocia a una importante diversidad de objetos muebles, entre los cuales la cerámica constituye el material más recurrente, $\mathrm{y}$, en este sentido, privilegiado para abordar aspectos culturales, cronológicos y funcionales de los sitios asociados.

En términos específicos, intentaremos, por una parte, mostrar cómo estos objetos pueden transitar por diferentes trayectorias durante su vida social (Appadurai 1991 [1986]), ampliando su función primordial de contenedor según los parámetros de cada contexto. En complemento, será importante comprender desde dónde, cómo y cuáles vasijas fueron transportadas, así como evaluar en qué medida las vasijas pueden constituir una proyección social sobre el espacio de tránsito, haciendo referencia a acciones y sentidos específicos inscritos por los mismos usuarios (cf. Amuedo 2010; Gell 1998). Desde la estrategia anterior haremos frente a nuestro principal desafío que se centra en el esclarecimiento de la funcionalidad de los sitios $y$, con base en ello, contribuir a la identificación de las prácticas sociales (sensu Núñez y Nielsen 2011) vinculadas a la ruta.

\section{La Arqueología Vial de la Región de Antofagasta}

Más allá de ser el espacio más árido del mundo, el desierto de Atacama está compuesto por múltiples oasis que, aunque acotados, presentan climas agradables, muy beneficiosos para la vida vegetal, animal y humana. En consecuencia, las poblaciones prehispánicas construyeron allí sus residencias principales, desde donde accedían a residencias secundarias o lugares de tarea, entre otros, ubicados en otros oasis menores, en medio del desierto (bajo los $2.500 \mathrm{msm}$ ) o en la estepa puneña (ca. 3.000-4.000 $\mathrm{msm}$ ). Desde la arqueología vial, los trabajos han reproducido el binomio nodo-internodo, el primero en referencia a las áreas de asentamiento permanente y el segundo en relación con las grandes extensiones de desierto atravesadas por las rutas prehispánicas (Berenguer 2004; Nielsen 2011; Núñez y Nielsen 2011; Pimentel 2012). 
En la región de Antofagasta, la arqueología vial se ha orientado a la realización de una tipología de rutas y al estudio sistemático de los contextos arqueológicos asociados. Con ello, se ha logrado relevar distintos segmentos de caminos que en el pasado prehispánico contribuyeron a la integración socioeconómica de la cuenca del Loa, y de ésta con la costa pacífica y el altiplano meridional. Entre ellos destacan las vías que conectaron la costa norte de Tocopilla con el Loa Medio vía Pampa El Toco y la ruta que une Tocopilla con Quillagua (Cases et al 2008; Pimentel 2003, 2012; Pimentel et al. 2010, 2011). Esto ha permitido constatar que, además de las caravanas, hubo otras estrategias de movilidad, como la de los costeros, quienes se adentraban al desierto en busca de materias primas líticas y recursos vegetales sin hacer uso de llamas cargueras (Briones et al. 2005; Pimentel et al. 2011). Junto con ello, se ha estudiado la ruta que comunicó San Pedro de Atacama con Quetena, en el Altiplano Sud Lipez (Pimentel et al. 2007) y recientemente, las rutas Caleta Huelén-Quillagua vía Calate, así como Quillagua-Calama vía Chug-Chug (Pimentel 2009, 2012).

La prospección intensiva realizada en esta última ruta aportó contextos arqueológicos novedosos, siendo especialmente elocuentes aquellos vinculados al ceremonialismo de los viajeros (Pimentel 2009). Esta situación tiene cierta coherencia con los antecedentes etnográficos referidos a la ritualidad en la que se enmarcan los viajes de los caravaneros en otras regiones del área Circumpuneña (Lecoq 1987; Nielsen 2000).

Resulta evidente que el emplazamiento de algunos de estos sitios se relaciona con puntos de transición entre paisajes contrastantes o lugares que poseen una amplia visibilidad del entorno. En estos casos encontramos pequeñas estructuras no habitacionales donde se ha depositado una cantidad significativa de mineral de cobre triturado y fragmentos de cerámica. De acuerdo con Pimentel (2009; Pimentel et al. 2011), los sitios ceremoniales operarían dentro de sistemas de diferenciación regional donde las estructuras de tipo "muros y cajas" referirían a la tradición Loa-San Pedro, las "líneas de piedras" podrían vincularse a la costa y las oquedades artificiales -o "sepulcros"- a un sistema circumpuneño más amplio.

Las características específicas de los sitios con presencia de material cerámico asociados a la ruta se sintetizan en la Tabla 1. Hemos incluido, además, cuatro hallazgos aislados que constituyen fragmentos o piezas fragmentadas sin otras asociaciones. Una de ellas se registra en las cercanías del sitio de geoglifos Chug-Chug Este 1, mientras que los otros fueron recuperados en los tramos Aguada/Chug-Chug 1, Chug-Chug/Montecristo y en Quebrada Montecristo (Figura 1).

\section{Criterios Metodológicos Utilizados para Analizar la Fragmentería}

Para documentar los contextos de uso y descarte de las vasijas a lo largo de la huella se consideró indistintamente toda la muestra recuperada, tanto de colectas de superficie como de sondeos, la cual arrojó material solo en el primer nivel. Esto se condice con contextos arqueológicos derivados de actividades muy acotadas, al paso de los viajeros.

La fragmentería fue registrada de acuerdo con sus características tecnológicas, morfofuncionales, decorativas y de conservación (Rice 1987; Shepard 1985 [1956]). Para aproximarnos a la cronología y proveniencia del material, se llevó a cabo una adscripción tipológica que se realizó siguiendo los trabajos de V. Varela $(1992,2002)$ y de M. Uribe y colaboradores (Uribe y Ayala 2004; Uribe 2004; Uribe et al. 2007). El considerable número de fragmentos que pudieron ser ensamblados $(10,1 \%)$, y el alto nivel de asignación de fragmentería a piezas individuales $(89,4 \%)$, permitieron una buena descripción morfológica tanto de las piezas como de las categorías de vasijas, además de la identificación del número mínimo de vasijas (NMV) presente en los sitios.

Se generó también una cuantificación que denominamos número calibrado de fragmentos (NCF), que reduce a uno el número de fragmentos que pertenecen a una misma vasija. En otras palabras, los grupos asignados a piezas individuales son representados como un solo fragmento y contabilizados de esa manera junto al resto de fragmentos que no pudo ser asignado a vasijas individuales. Lo anterior permite calibrar las frecuencias tipológicas, ya que, de otro modo, el tamaño y espesor variable de las vasijas produce diferenciales considerables en la cantidad de fragmentos resultantes, sobrerrepresentando algunos tipos cerámicos, especialmente los relacionados con vasijas de mayor tamaño (p.ej., TRB), problema ya señalado en la literatura (p.ej., Rice 1987:198).

Para identificar qué tipo de vasijas fueron usadas en los sitios, el material cerámico fue abordado a 


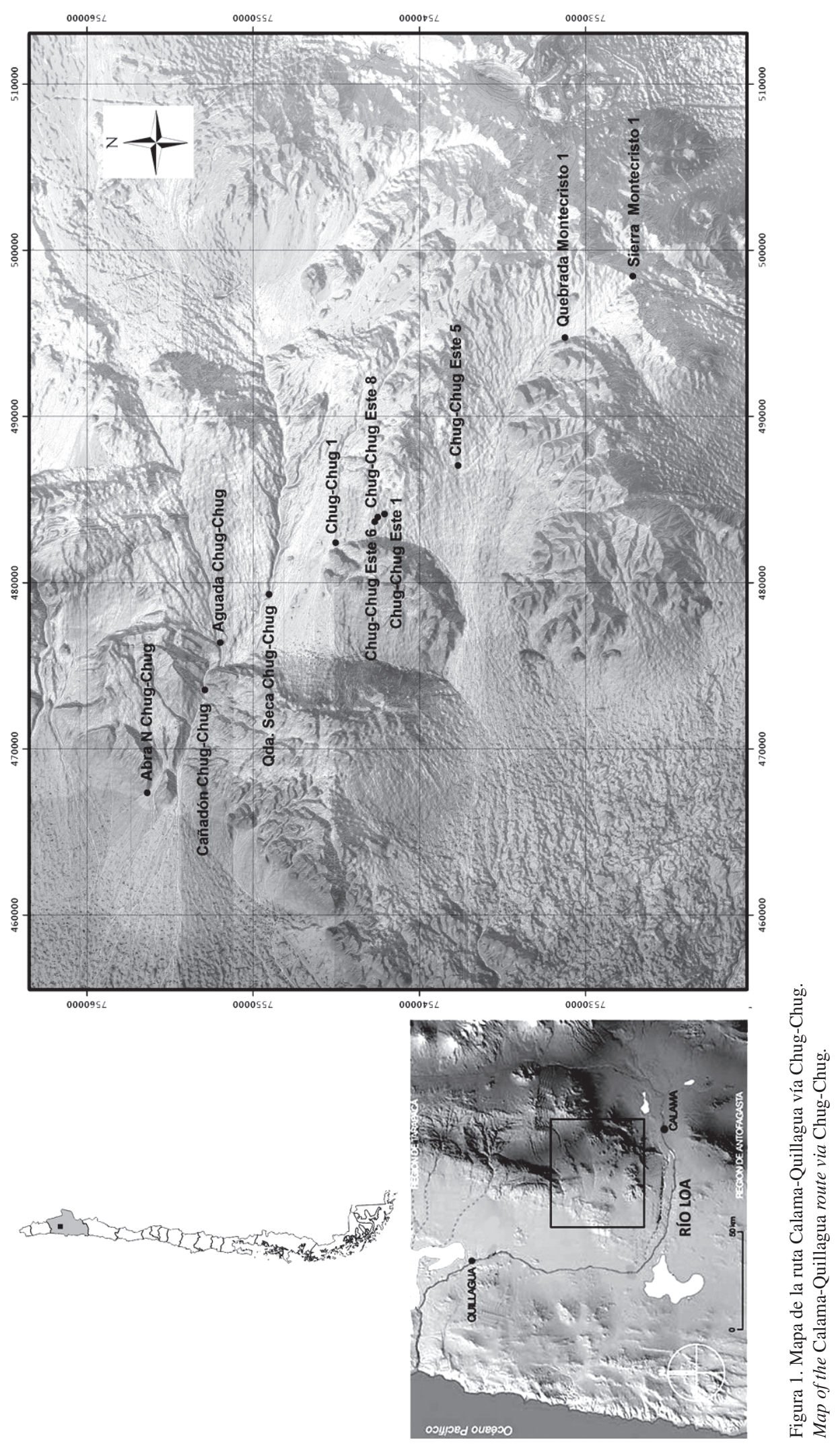




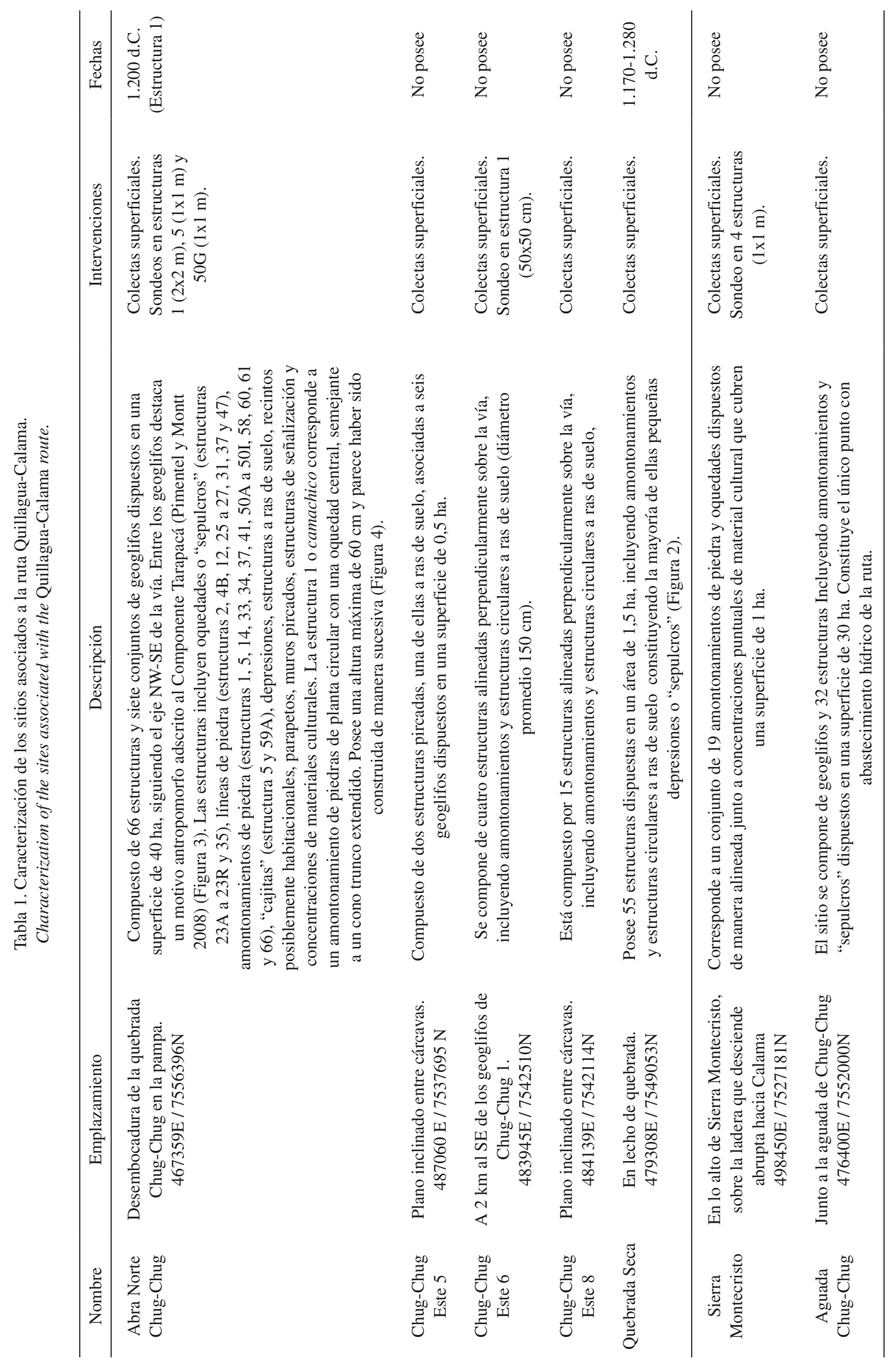




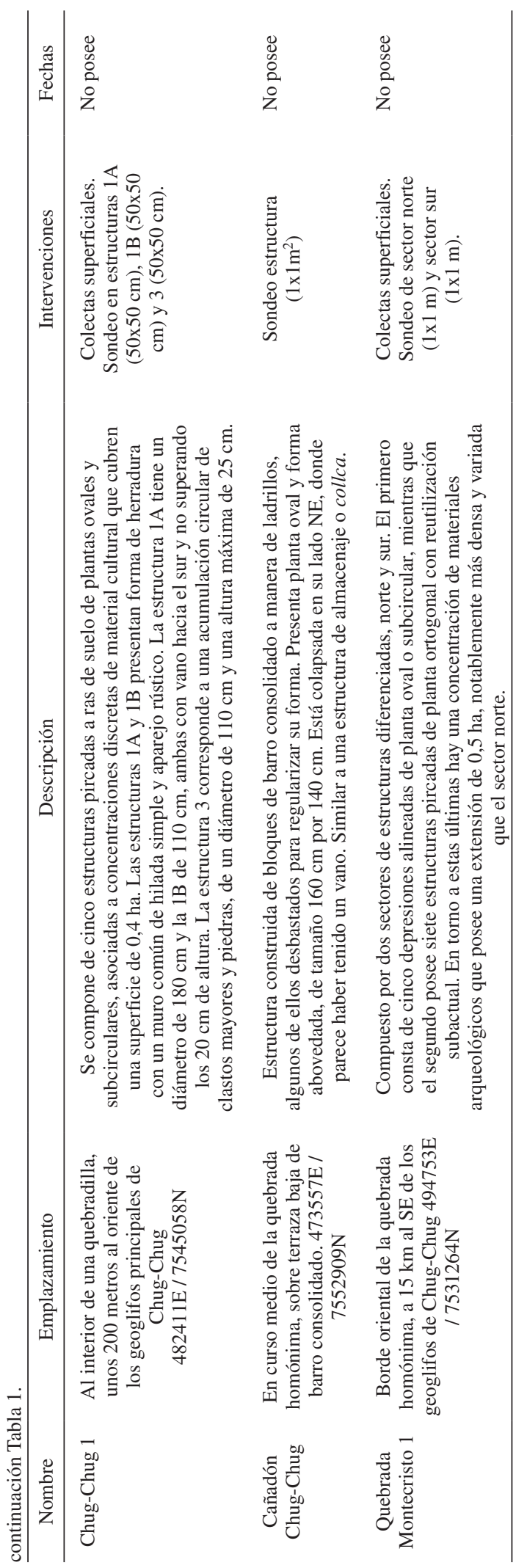

partir de las categorías morfofuncionales presentes, las cuales fueron construidas a partir de un análisis múltiple que incluyó la aplicación de proyecciones generales de tamaño y capacidad de contención -derivadas de los diámetros de borde y cuerpo disponibles-, la observación de huellas de uso y la revisión de documentación etnohistórica y etnográfica pertinente. Complementariamente, se incluyó información propia del contexto arqueológico, con especial atención a los procesos de formación de sitio y los otros materiales culturales asociados.

\section{Las Tradiciones Alfareras}

Los restos cerámicos recuperados en los sitios suman un total de 2.888 fragmentos, de los cuales el $92,04 \%$ proviene de recolección superficial y el 7,96\% proviene de sondeos. Esta marcada diferencia se explica por la ausencia de secuencias estratigráficas domésticas, detectándose sólo sitios superficiales. Asimismo, más del $80 \%$ del material se concentra en el sitio Abra Norte Chug-Chug, específicamente al interior de las estructuras, en asociación a geoglifos y líneas de piedra o disperso en distintos puntos del Abra (Figura 2). Del total de fragmentos analizados en la ruta se identificó un mínimo de 131 vasijas (NMV) y se definió un NCF de 434 unidades (Tablas 2 y 3 ).

Por otra parte, se reconocieron 27 tipos cerámicos pertenecientes a cinco tradiciones alfareras que abarcan unos mil años de historia, desde alrededor del siglo IV de nuestra era hasta el periodo colonial o etnográfico. De ellas, el componente Loa-San Pedro constituye el más representado con un $84,8 \%$ del NCF. Considerablemente menores son las frecuencias del componente Tarapacá (4,5\%), seguido por los tipos del Noroeste Argentino (3,1\%), del Altiplano Circumtiticaca y Meridional $(1,6 \%)$ y del Cuzco $(0,4 \%)$ (Tabla 2, Figura 3).

\section{Componente Loa-San Pedro}

En primer lugar registramos fragmentos cerámicos del periodo Medio (ca. 400-900 d.C.), asociados a la influencia Tiwanaku en el Salar de Atacama. Estos se encuentran representados por dos piezas no restringidas del tipo Coyo (COY) halladas sobre la ruta en Abra Norte y en Sierra Montecristo. Hay también tres piezas del tipo San Pedro Negro Pulido (SNP), correspondientes a tazones o variantes NP3 (sensu Uribe 2004) en Abra 
Norte y un fragmento aislado en Quebrada Seca. Las piezas Coyo presentan la característica decoración incisa con diseños geométricos y campos reticulados en el cuerpo y banda de borde (cf. Munizaga 1963; Tarragó 1989; Uribe 2004). Las SNP son representativas de la especialización alfarera en el oasis San Pedro, apareciendo en sitios funerarios de este periodo (Uribe 2004).

Para el periodo Intermedio Tardío (ca. 9001.450 d.C.) se registraron ocho tipos cerámicos,

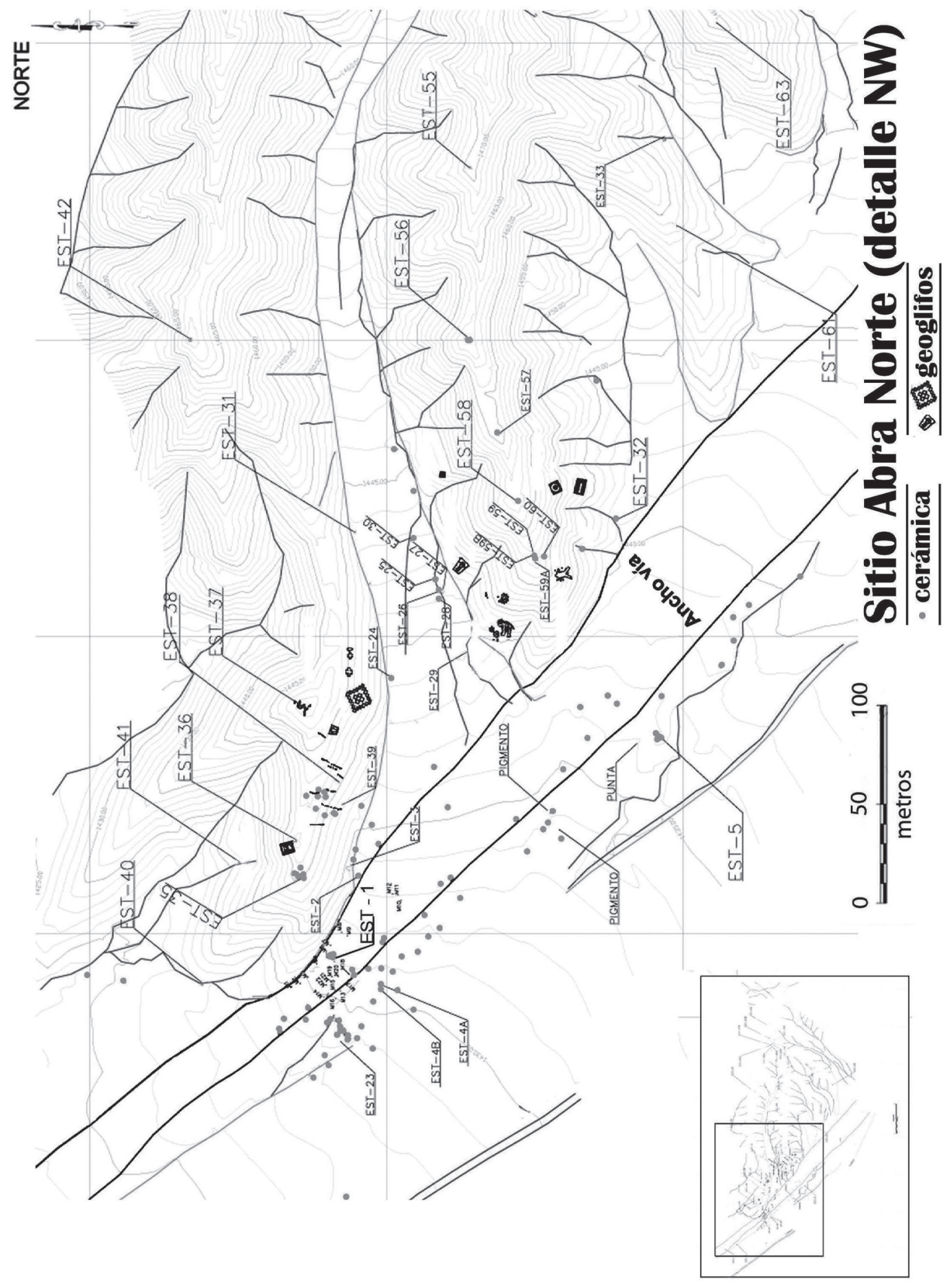

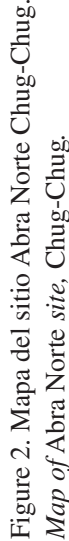




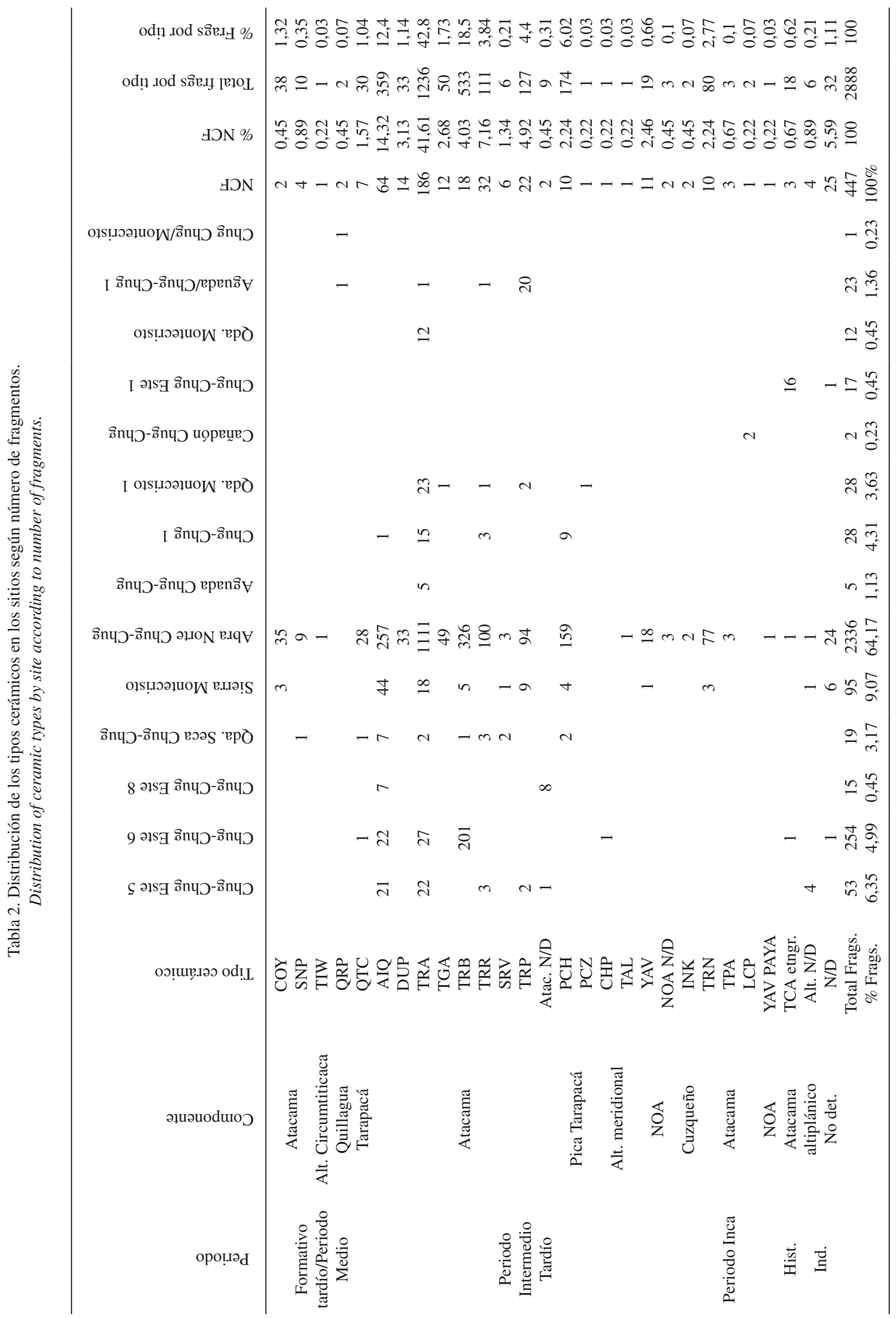




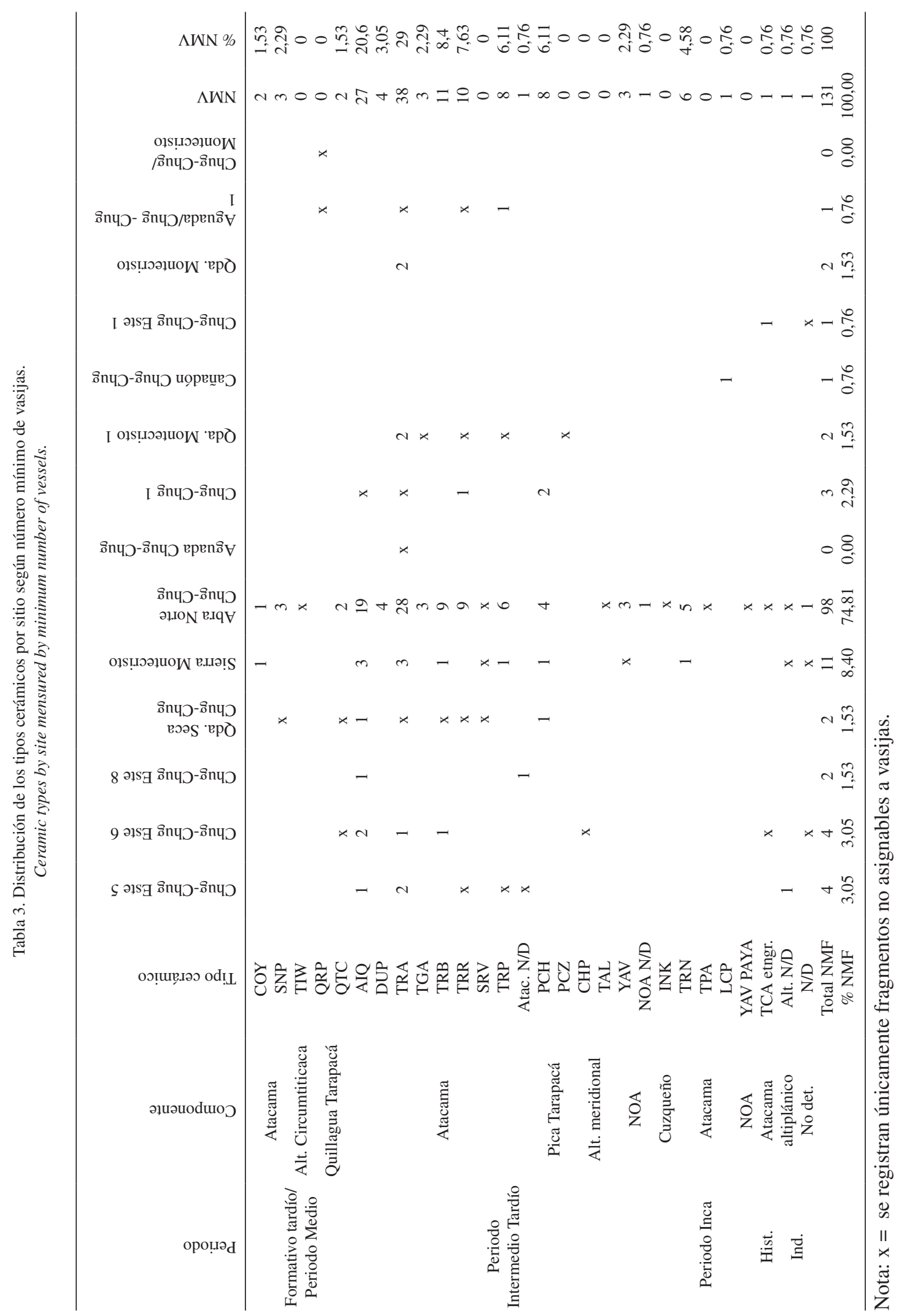




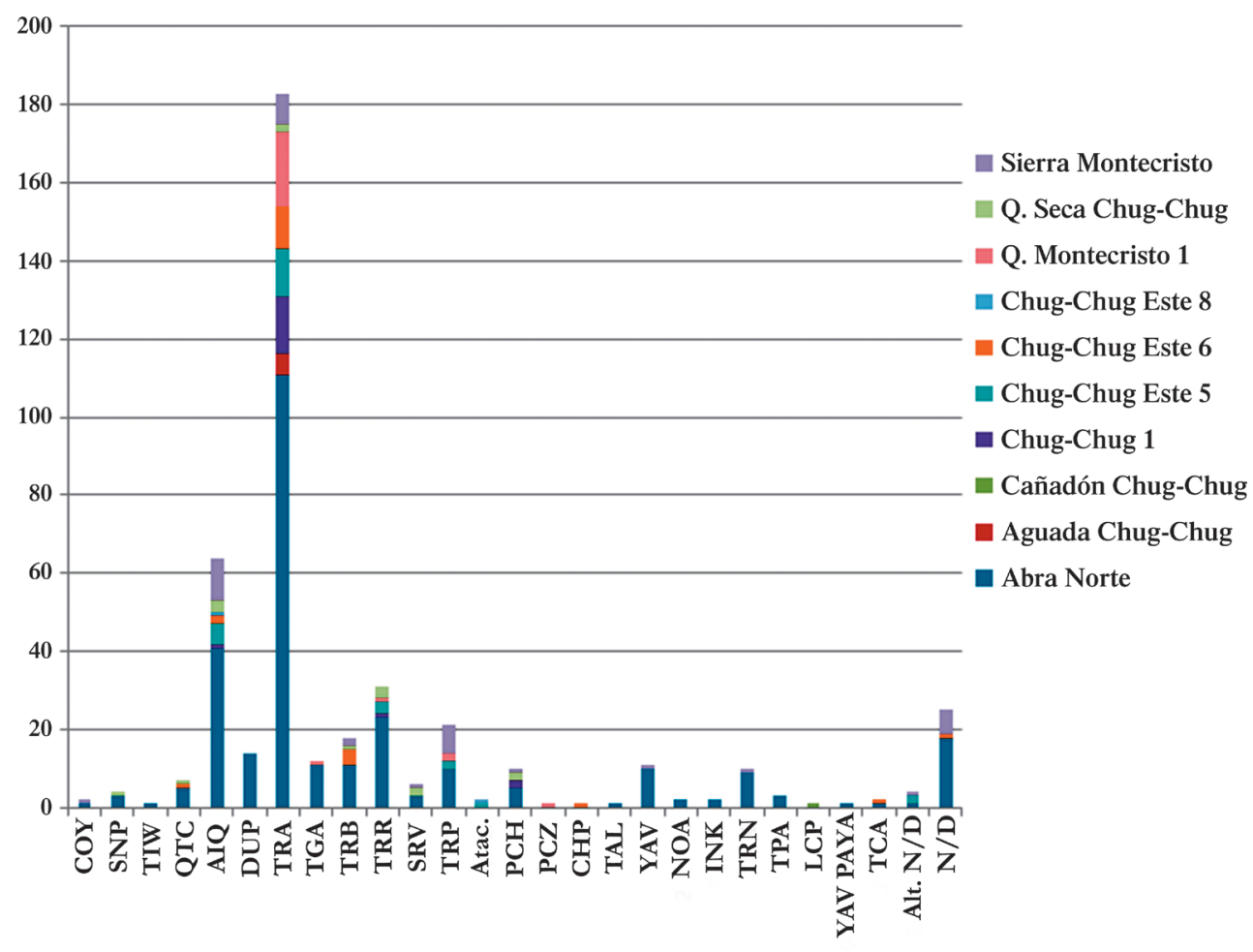

Figura 3. Tipos cerámicos según sitios arqueológicos.

Ceramic types by archaeological sites.

predominando los cántaros Turi y variantes, así como las escudillas. El más abundante corresponde al tipo Turi Rojo Alisado (TRA) con un NCF de 186 dentro de los cuales se identifica un mínimo de 38 vasijas distribuidas en la mayor parte de los sitios, 28 de ellas en Abra Norte. TRA constituye la cerámica más característica en las cuencas del Loa y el Salar de Atacama, presentando en general formas restringidas. Le siguen en frecuencia las escudillas del tipo Ayquina (AIQ), contabilizándose un NCF de 64 y un mínimo de 27 piezas distribuidas en Chug-Chug 1, Chug-Chug Este 5, Chug-Chug Este 6, Chug-Chug Este 8, Quebrada Seca, Sierra Montecristo y Abra Norte, este último concentrando 19 ejemplares. De este tipo, destacan dos piezas grabadas post-cocción de grandes dimensiones, con diámetro de 220 a $240 \mathrm{~mm}$ en el borde. Una de ellas presenta al interior la figura esquemática de un camélido, mientras que la otra posee diseños reticulados burdos en la superficie interior, grabados con una herramienta cortopunzante muy fina (Figura 4a). Por otra parte, se registran cuatro escudillas del tipo Dupont (DUP) únicamente en Abra Norte. Tal como las vasijas TRA, ambos tipos de escudillas poseen una amplia distribución incluyendo San Pedro de Atacama, Alto Loa, Toconce, Caspana, Turi, Lasana, Chiu Chiu, Chacance, Quillagua, Caleta Huelén y Pica, en un rango temporal situado entre el 800 y 1400 d.C. (Uribe 2004). Les siguen en frecuencia las escudillas del tipo Turi Rojo Revestido Pulido (TRP), con ocho vasijas identificadas y un NCF de 22, distribuidas en los sitios Chug-Chug Este 5, Sierra Montecristo y Abra Norte. Estas piezas presentan cierta relación tecnológica con los tipos AIQ y DUP, aunque aparentemente predominan en época posterior al 1.400 d.C. (Uribe 2004).

Por otra parte, si bien fueron adscritos 533 fragmentos al tipo TRB, estos dan cuenta sólo de un NCF de 18, identificándose un mínimo de 11 piezas, lo que se explica por la enorme cantidad de fragmentos provenientes de cada una de estas vasijas de gran tamaño. Nueve de ellas se concentran en Abra Norte, mientras que el resto se registra en Quebrada Seca, Sierra Montecristo y Chug-Chug Este 6. TRB se asocia a vasijas restringidas independientes con asas remachadas laterales, a veces con un revestimiento blanco exterior, datadas entre el 980 y 1560 d.C. (Uribe 2004). 

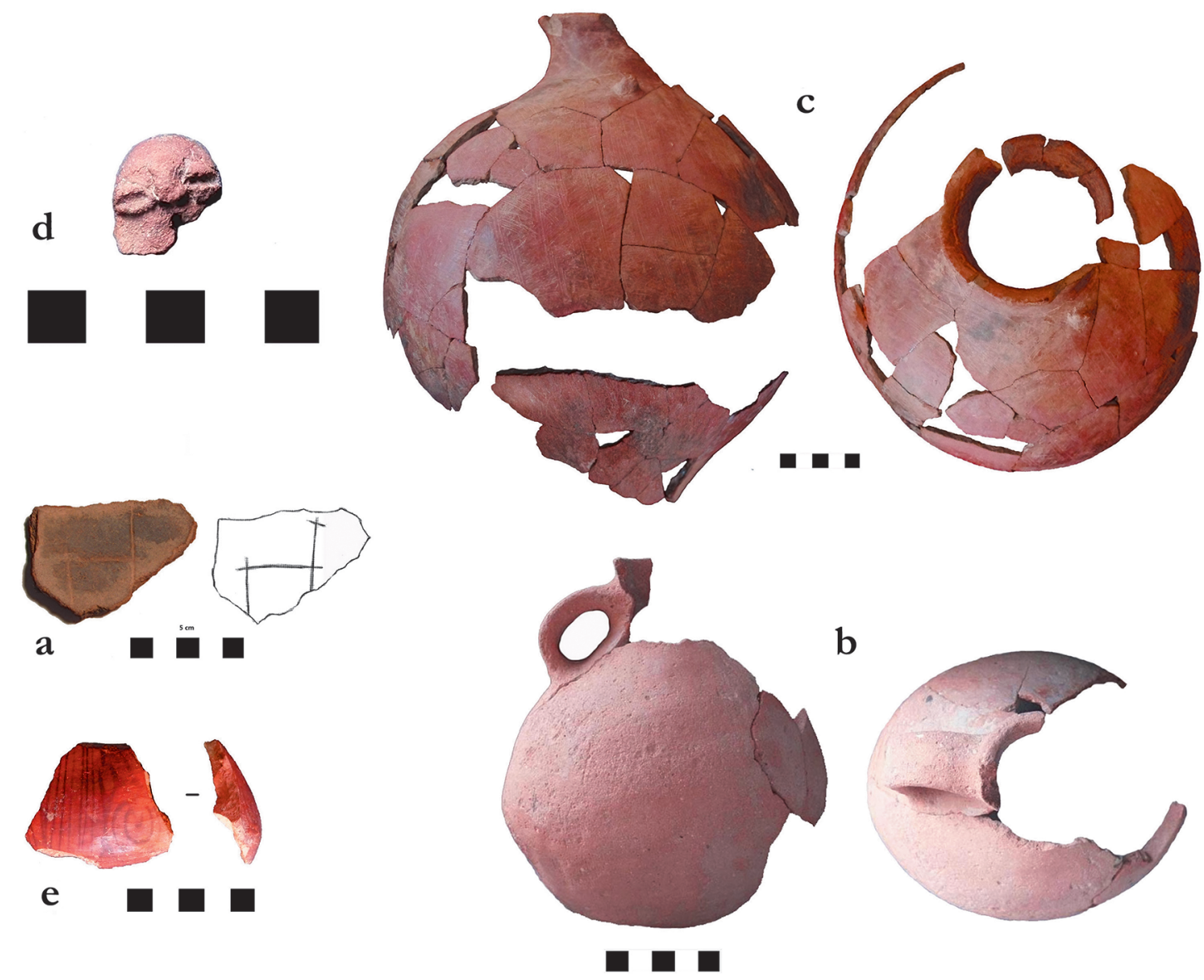

b

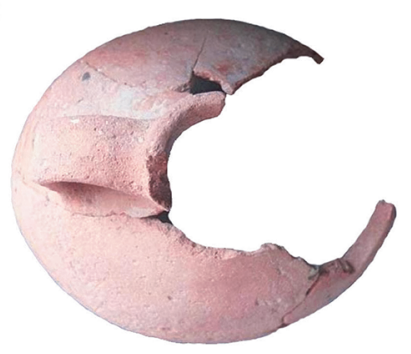

Figura 4. (a) Fragmento AIQ decorado con grabado abstracto de camélido (Abra Norte). (b) Pieza TCA etnográfica reconstruida (Chug-Chug Este). (c) Pieza PCH reconstruida (Abra Norte). (d) Fragmento modelado PCZ (Qda. Montecristo 1). (e) Fragmento de pequeño aríbalo Yavi La Paya (Abra Norte). Escala: $5 \mathrm{~cm}$.

Decorated AIQ sherd with abstract camelid engraving (Abra Norte). (b) Reconstructed ethnographic TCA (Chug-Chug Este). (c) Reconstructed PCH vessel (Abra Norte). (d) Modeled PCZ sherd (Qda. Montecristo 1). (e) Small Yavi La Paya aríbalo sherd (Abra Norte). Scale: $5 \mathrm{~cm}$.

En una proporción similar se registraron diez piezas (NCF de 32) del tipo Turi Rojo Revestido (TRR), principalmente en Abra Norte, aunque también en Quebrada Seca, Chug-Chug 1, Chug-Chug Este 5, Quebrada Montecristo 1 y como hallazgo aislado en el tramo Aguada/Chug-Chug 1. TRR es tecnológica y morfológicamente similar a TRA, pero presenta un revestimiento rojo exterior que le conferiría un carácter más ceremonial, recurrente en contextos funerarios y sitios con arte rupestre de la región (Varela 1992; Uribe 2004).

Asimismo, hay seis fragmentos del tipo San Pedro Rojo Violáceo (SRV) en los sitios Abra Norte, Quebrada Seca y Sierra Montecristo. SRV corresponde a piezas restringidas pulidas y con cuello, muchas veces abultado, donde pueden registrar decoraciones modeladas antropomorfas. Se distribuye por toda la cuenca del Loa y el Salar de Atacama en un rango temporal entre el 800 y 1300 d.C. (Tarragó 1989; Uribe 2004).

Por último, el tipo atacameño menos representado del Intermedio Tardío es el Turi Gris Alisado (TGA), con un NCF de 12 y tres vasijas identificadas, distribuidas en Quebrada Montecristo 1 y en la Estructura 1 de Abra Norte, donde varios fragmentos de una sola pieza presentan abundantes residuos de una sustancia resinosa reducida por quema en la superficie interior. TGA corresponde a ollas de cuerpo esférico con asas labio-adheridas, datadas hacia el 1.200-1.500 d.C. (Uribe 2004), cuya baja frecuencia en la ruta consideramos coherente con la ausencia de contextos domésticos. 
Los tipos tardíos (ca. 1.450-1.530 d.C.) se asocian principalmente a expresiones inka locales correspondientes a Turi Rojo Revestido ExteriorNegro Alisado Interior (TRN), Turi Rojo Revestido Ambas Caras (TPA) y Lasana Café Rojizo Revestido Pulido Ambas Caras (LCP). El primero es el más abundante, con seis piezas (NCF de 10) distribuidas en Abra Norte y Sierra Montecristo. Se trata de aríbalos de cuerpo ovoide o elipsoide con cuellos marcadamente hiperboloides y un par de asas en arco de correa adheridas en caras opuestas del diámetro máximo del cuerpo. Uno de sus rasgos más característicos es el tratamiento diferencial de las superficies, pulidas y revestidas con pigmento rojo exterior hasta el interior del cuello, y alisadas, rasmilladas y oscurecidas por dentro (Uribe 2004). Por su parte, TPA se registró en Abra Norte a partir de tres fragmentos, mientras que LCP se contabilizó una pieza en Cañadón Chug-Chug. TPA y LCP se asocian a escudillas decoradas, entre las cuales las TPA reproducen formas clásicas incaicas de aspecto ornitomorfo (Uribe 2004).

Finalmente, se registraron tres unidades NCF adscritas al tipo Turi Café Alisado (TCA) en su variante etnográfica. Una de ellas corresponde a una vasija restringida independiente, que presenta un alto nivel de restauración, hallada de forma aislada en el sector de Chug-Chug Este (Figura 4b). Dicho tipo cerámico conformaría una tradición alfarera etnográfica propia de las tierras altas heredera de los tipos tardíos mencionados donde se combinan elementos indígenas y europeos, característica por sus pastas con abundante mica (Uribe 2002; Varela 1992).

\section{Componente Tarapacá}

Prácticamente contemporáneos a los tipos LoaSan Pedro del periodo Medio son los del Formativo Tardío de Tarapacá (ca. 0-900 d.C.). De este periodo registramos un total de dos vasijas del tipo Quillagua Tarapacá Café Amarillento (QTC) con un NCF de 7 y dos fragmentos del tipo Quillagua Rojo Pulido (QRP). El primero constituye la cerámica más representativa del Formativo Tardío en el oasis de Quillagua y valles de Tarapacá, mientras que el segundo constituye más bien una expresión poco frecuente. QTC incluye una variedad considerable de formas, incluyendo miniaturas, como cuencos, pocillos, ollas o vasos-floreros usados en contextos funerarios y domésticos (Ayala 2001; Ayala y Uribe
2001; Agüero 2004; Uribe 2004; Uribe et al. 2007). Por su parte, el tipo QRP se asocia a piezas no restringidas y restringidas independientes, vinculadas a vasos y botellas que pueden presentar mamelones en el borde o cuello (Uribe et al. 2007).

Los fragmentos QTC se registran en Abra Norte, en Quebrada Seca y Chug-Chug Este 6. Por otra parte, los fragmentos QRP fueron registrados aislados en el tramo Aguada/Chug-Chug 1 y en el tramo Chug-Chug/Montecristo.

El período Intermedio Tardío (ca. 900-1.450 d.C.) está representado a partir de los tipos Pica Charcollo (PCH) y Pica Chiza (PCZ), ambos con rango temporal entre 750 y 1.450 d.C. (Uribe et al. 2007). PCH constituye la cerámica más popular de Tarapacá, presentándose en contextos domésticos y funerarios de todos los pisos altitudinales de la región, a saber, costa (p.ej., cementerios Bajo Molle, Los Verdes y Patillos), valles bajos (p.ej., Caserones, Huarasiña, Tilivilca, Arias, Pachica), oasis interiores (p.ej., Pica 8,), quebradas precordilleranas (p.ej., Camiña, Nama, Chuzmiza y Jamajuga) y altiplano (p.ej., Pukar Coyu) (Núñez 1965; Moragas 1995; Uribe et al. 2007). Se contabilizaron ocho piezas $\mathrm{PCH}(\mathrm{NCF}=10)$ distribuidas en Abra Norte, Quebrada Seca, Chug-Chug 1 y Sierra Montecristo. Para PCH son comunes las botellas de cuello angosto, cuerpo esférico, superficie rasmillada con restos de revestimiento rojo disparejo y protúberos o mamelones en la unión cuello/cuerpo (Figura 4c). El tipo PCZ está representado por un único fragmento que muestra un rostro modelado antropomorfo hallado en superficie, al interior de una estructura ortogonal en el sector sur de Quebrada Montecristo 1 (Figura 4d).

\section{Componentes Altiplánicos, Noroeste Argentino e Inka}

Se registró un fragmento polícromo Tiwanaku (TIW) en la superficie de Abra Norte. Se trata de un pequeño fragmento de kero con decoración abstracta conformada por una línea blanca fina entre dos campos rojizo y negro, que nos remite al Altiplano Circumtiticaca o posiblemente a sus centros periféricos de Moquegua o Cochabamba. Vasijas de este tipo han sido previamente registradas en contextos funerarios del oasis de San Pedro de Atacama en los cementerios de Larrache, Quitor 5, Solor 3 y Solcor 3 (Tarragó 1989; Uribe 2004). En este sentido, es importante señalar que los contactos de San Pedro con este ámbito se manifiestan 
ya desde el Formativo Tardío, con la aparición de tabletas con iconografía tiwanaku, nexos que se intensifican y diversifican durante el Periodo Medio con circuitos de interacción que incluyen además el Altiplano Meridional y el Noroeste Argentino (Llagostera et al. 1988; Tarragó 1989).

De la tradición altiplánica también se registró un fragmento de vasija tipo Chilpe (CHP) y un fragmento de pieza no restringida del tipo Taltape (TAL), hallados en Chug-Chug Este 6 y Abra Norte, respectivamente. Ambas se vinculan al altiplano de Carangas con fechas entre el 1.200 y 1.400 d.C., siendo TAL también vinculado etnográficamente a comunidades Quillacas. Estos tipos han sido anteriormente hallados en la sierra y altiplano de Tarapacá en asociación a alfarería de tipo Isluga y variantes (Sanhueza y Olmos 1981; Uribe et al. 2007).

Por otra parte, se registraron piezas provenientes del Noroeste Argentino vinculadas a los periodos Intermedio Tardío (ca. 900-1.450 d.C.) y Tardío (ca. 1.450-1.530 d.C.). Con relación a las primeras, se cuantificó un mínimo de tres vasijas restringidas (NCF de 11) de tradición Yavi (YAV), en Abra Norte y Sierra Montecristo. Se caracterizan por pastas arcillosas muy compactas y coladas de coloración anaranjada, en general pulidas por el exterior y, en un caso, con revestimiento rojo. Por último, se identificó un fragmento del cuerpo medial y unión cuello/cuerpo de un aríbalo Yavi La Paya en Abra Norte, propio de la quebrada de Huamahuaca y los valles Calchaquíes en tiempos incaicos. Se caracteriza por una pasta muy colada y compacta, superficie exterior pulida con pintura negra sobre revestimiento rojo, delineando trazos muy finos que configuran un espiral, volutas y rectas paralelas muy características de este tipo cerámico (Figura 4e).

Por último, se hallaron dos fragmentos de piezas restringidas incaicas (INK) en Abra Norte. Ambos presentan pasta colada y resistente, de coloración anaranjada, cuyas superficies exteriores se encuentran pulidas o bruñidas y revestidas de rojo.

En síntesis, podemos señalar que las vasijas del componente Loa-San Pedro del Intermedio Tardío son las más frecuentes, predominando el tipo TRA, seguido por AIQ y luego TRB, TRR y TRP. Las cerámicas formativas y del Periodo Medio así como los otros componentes alfareros (Tarapacá, altiplánico, Noroeste Argentino e Inka) poseen una representación menor, no obstante, vienen a complementar los antecedentes que disponemos sobre las relaciones de interacción de Atacama con sus regiones vecinas y con los principales centros de poder durante la hegemonía Tiwanaku e Inka (Tabla 2).

\section{Morfología, Uso y Patrones Distribucionales de las Vasijas}

El análisis cuantificó un mínimo total de 131 vasijas (NMV), a partir de las cuales se reconocieron tres categorías morfofuncionales (Rice 1987; Shepard 1985 [1956]): restringidas independientes o con cuello (cántaros, urnas, botellas, jarros, aríbalos, ollas), no restringidas de contorno simple (escudillas y vasos) y restringidas no determinadas $(\mathrm{n} / \mathrm{d})$. Estas últimas son fragmentos con rasgos propios de piezas restringidas, pero que no permiten determinar si presentan gollete. Sin diferenciar tradición o período, las vasijas más frecuentes corresponden a formas restringidas independientes con un mínimo de 64 piezas (64\% del NCF). Le siguen las escudillas con 38 piezas $(23,9 \%) \mathrm{y}$, en menor medida, se registran vasijas restringidas $\mathrm{n} / \mathrm{d}$ $(7,4 \%)$. Asimismo, la variante vasos incluye sólo 2 piezas y algunos fragmentos $(0,9 \%)$. Un $6,9 \%$ de la muestra quedó indeterminada.

Por otra parte, de acuerdo con la relación de forma y tamaño de las vasijas, pudimos distinguir tres grandes grupos: las escudillas, que representan piezas medianas a pequeñas con diámetros máximos de borde entre 120 y $240 \mathrm{~mm}$ (Figura 5a); los grandes contenedores restringidos independientes con diámetros de boca entre 120 y 300 mm (Figura 5b); y los contenedores restringidos independientes de tamaño mediano, con diámetros de gollete menores a $80 \mathrm{~mm}$, en general jarros de cuello angosto, botellas y aríbalos.

Las piezas restringidas independientes corresponden principalmente a cerámica Loa-San Pedro, donde los contenedores TRA son los más frecuentes $(64,8 \%)$, seguidos por TRR y TRB $(11,1 \%$ y $6,3 \%)$, todos ellos del periodo Intermedio Tardío, además de piezas TRN (3,5\%) del periodo Tardío. El componente Tarapacá se ve representado por las botellas PCH $(3,5 \%)$. Al considerar las proyecciones de tamaño, los tres primeros tipos se asocian a piezas de mediano a gran tamaño, con diámetros de boca que oscilan entre los 90 y $300 \mathrm{~mm}$. En cambio, las piezas TRN y $\mathrm{PCH}$, asociadas a aríbalos o aribaloides y botellas respectivamente, evidencian tamaños menores y golletes más angostos $(80 \mathrm{~mm})$, con lo cual podemos hablar de dos subgrupos morfofuncionales. 

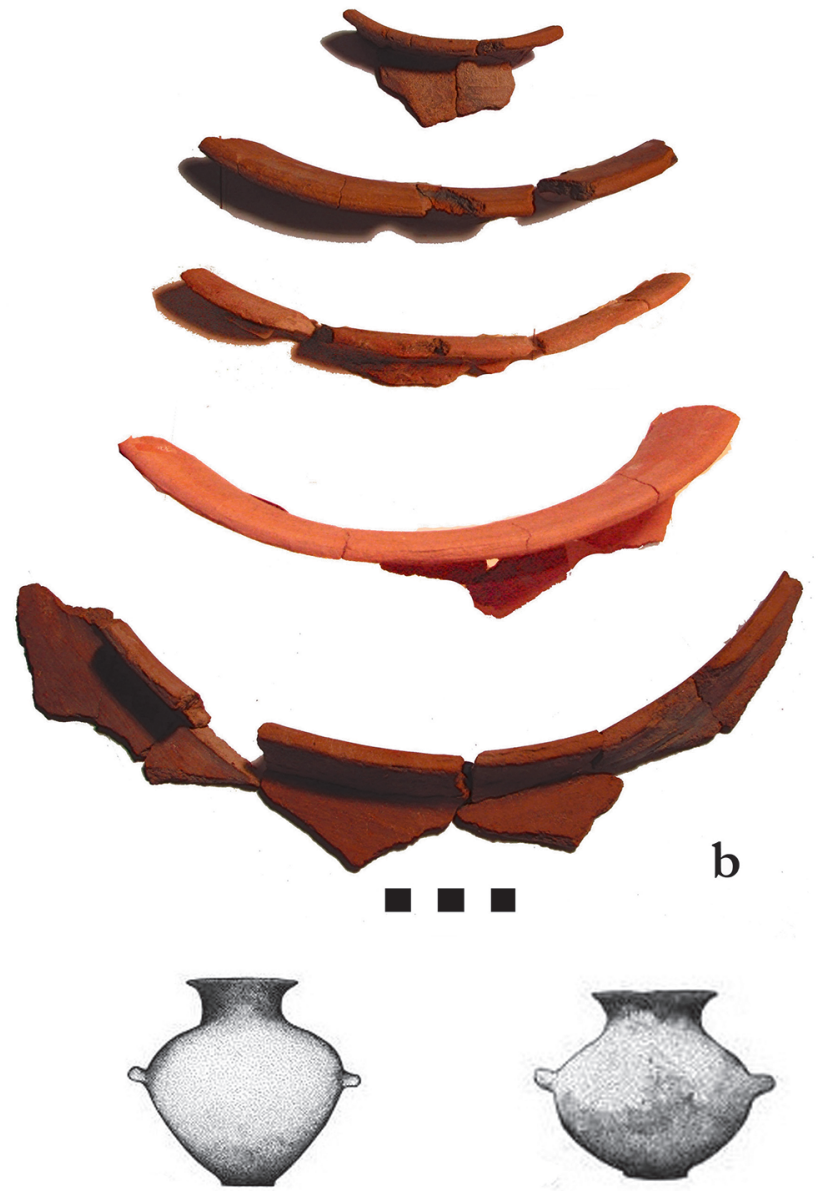

Figura 5. Diámetros de borde según categoría de vasija y referentes morfológicos: (a) Grandes contenedores restringidos (TRA). (b) Vasijas no restringidas (AIQ y TRP). Dibujos referenciales modificados de Uribe 2004. Escala: $5 \mathrm{~cm}$.

Rim diameters by vessel category and morphological type. (a) Large restricted urns (TRA). (b) Non restricted vessels (AIQ and TRP). Reference designs modified from Uribe 2004. Scale: $5 \mathrm{~cm}$.
Los tamaños más bien pequeños de las escudillas podrían asociarse al uso individual. Estas se encuentran representadas por el tipo AIQ $(59,8 \%)$, TRP $(20,6 \%)$, TPA $(2,8 \%)$, DUP $(13,1 \%)$ y COY $(1,9 \%)$. Cabe mencionar la existencia de vasos, representados por SNP y TIW del período Medio. A pesar de que Abra Norte concentra la mayor parte de la cerámica estudiada, se observa que tanto escudillas como contenedores restringidos se distribuyen prácticamente en todos los sitios de la ruta.

En términos generales, se considera que las vasijas restringidas independientes de mayor tamaño, como urnas, tinajas y aríbalos, presentan un diseño óptimo para el almacenaje. Asimismo, las vasijas para consumir y servir alimentos serían típicamente menores, de paredes más delgadas y no restringidas para optimizar el acceso al contenido, con bases
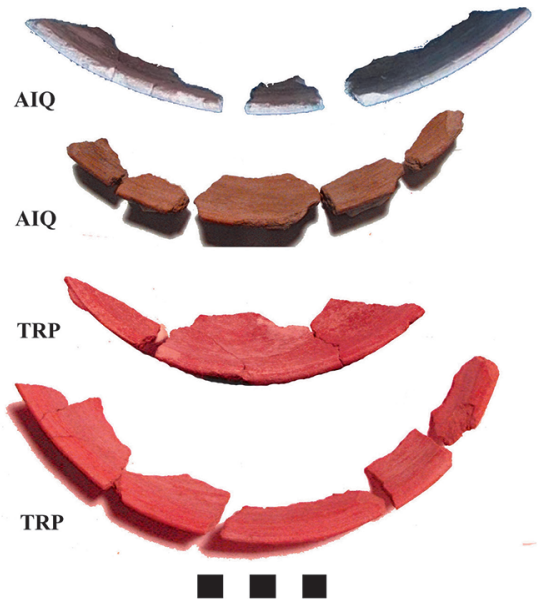

a

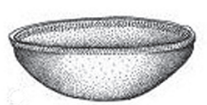

estables, como platos y cuencos. Las piezas para procesamiento de alimentos poseen morfologías más bien globulares o cónicas, carentes de ángulos y de bocas anchas, como ollas y cuencos (Eerkens 2004; Henrickson y McDonald 1983; Rice 1987). Esto se condice con las características generales de las dos categorías morfofuncionales más representativas de la muestra. Los grandes contenedores restringidos independientes evidencian escasas huellas de uso, entre los cuales sólo TGA registró adherencias de hollín, mientras que las escudillas muestran en algunos casos rasmillados diametrales en el interior.

Complementariamente, desde la información etnohistórica y etnográfica disponible (Tablas 4.1 y 4.2) reconocemos que los tipos TRA y TRR, que enfatizan conductas de almacenamiento (Uribe 2004), pueden ser vinculadas con algunos 


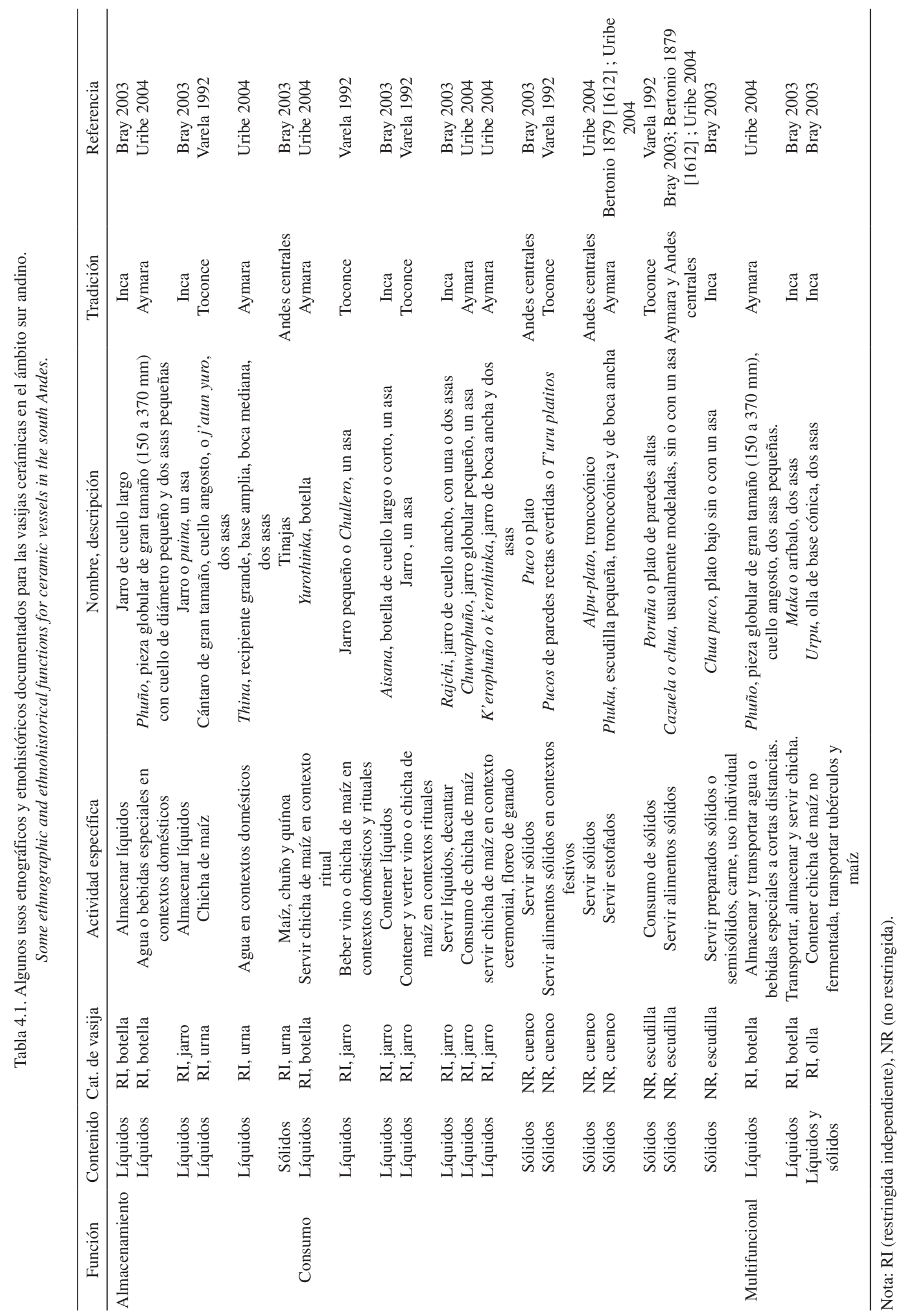




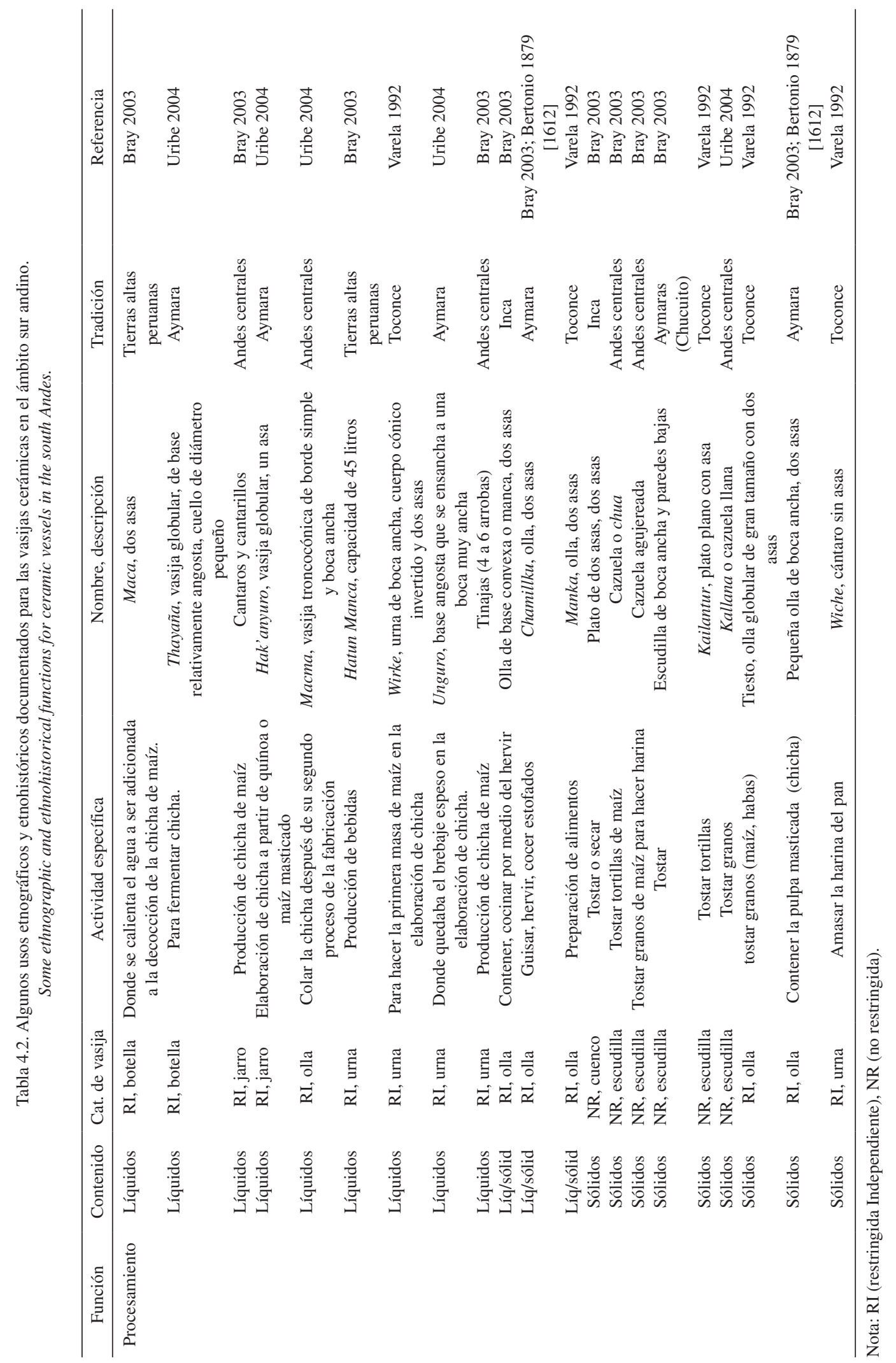


ejemplares etnográficos denominados wirkes y cántaros (Grupo 1, sensu Varela 1992) utilizados en la manufactura de la masa de maíz para la preparación de chicha y para su almacenamiento. Las "urnas" TRB se relacionan funcionalmente con el almacenamiento y conservación de líquidos (Varela 1992). Por otro lado, los distintos tipos de escudillas se asocian al servicio y consumo, pudiendo corresponderse con los platos etnográficos de servicio individual o t'uru documentados por Varela (1992). Cabe señalar que las ollas TGA se registran de manera escasa dentro de la muestra, y pueden asociarse a los tiestos utilizados para tostar habas o maíz (Varela 1992). La baja frecuencia de este tipo de vasijas con hollín es coherente con la ya mencionada ausencia de contextos de descanso o fogones domésticos.

A partir de varios casos observados en el mundo andino, se desprende que las escudillas y platos se utilizan para procesar alimentos sólidos o semisólidos, como tostar granos o elaborar tortillas, pero fundamentalmente para servirlos y consumirlos en situaciones domésticas y ceremoniales (Cobo 1964 [1653]; Lehnert 1988 en Uribe 2004; Tschopik 1950 en Bray 2003; Varela 1992). En los contextos de tránsito de Chug-Chug, las piezas no evidencian exposición al fuego, pero sí rasmillado interior por uso. Por su parte, los grandes contenedores restringidos han sido descritos en la literatura para el procesamiento, almacenamiento y transporte de chicha de maíz (Cobo 1964 [1653]; Uribe 2004; Varela 1992), como el aríbalo o maka incaica (Bray 2003) o el phuño aymara (Uribe 2004), siendo el primero usado también para almacenar y servir. Teniendo en cuenta el contexto de movilidad en el que se registran estas vasijas, consideramos que el subgrupo de botellas y/o aríbalos de mediano tamaño y cuello más angosto (TRN y $\mathrm{PCH}$ ) pudieron ser utilizados para transportar esta clase de bebidas o agua. Los registros sobre el fomento del comercio caravanero del vino y el aguardiente durante el apogeo de la minería en Potosí -siglos XVI y XVII- señalan que este se llevó a cabo mediante el uso de contenedores cerámicos de estas dimensiones, con capacidad de hasta nueve litros cada uno (Lecoq 1998).

Las vasijas mayores (TRA, TRR y TRB) pudieron ser usadas para transportar líquidos, pudiendo también incluir alimentos, como harinas. Sin embargo, el peso de la carga, sobre todo en el caso de TRB, nos lleva a pensar en la posibilidad de que estas vasijas fueran trasladadas vacías para cumplir otras funciones en los lugares de destino, como almacenaje o procesamiento de alimentos, ya que en la literatura etnohistórica y etnográfica se reconoce que el peso máximo que soporta la llama no supera los 35 kilos (Lecoq 1987, 1998).

\section{Relaciones Contextuales de la Cerámica en los Sitios de Ruta}

En primer lugar, se observa la existencia de cinco contextos que tienen en común la presencia de mineral de cobre triturado o challa, disperso a modo de ofrenda en estructuras de tamaño pequeño: Chug-Chug Este 5, Chug-Chug Este 6, Chug-Chug Este 8, Quebrada Seca y Sierra Montecristo. A pesar de que los sitios presentan otros materiales culturales (Tabla 5), es fuerte la asociación entre cerámica fracturada y mineral de cobre. Esto sucede en las dos estructuras de Chug-Chug Este 5, en una de las cuatro estructuras en Chug-Chug Este 6 y en tres de los cuatro amontonamientos de piedra de Chug-Chug Este 8 que presentan fragmentería cerámica. Los 53 "sepulcros" de Quebrada Seca presentan ambos elementos, registrándose también desechos líticos, pigmento, cuentas discoidales, algarrobo, maíz, restos malacológicos y leñosos (Figura 6). Por último, en Sierra Montecristo, ocho de los 19 amontonamientos de piedra presentan esta asociación, siendo que en cuatro de ellos existen otros materiales (Tabla 5).

En segundo lugar se registraron tres sitios que presentan estructuras y rasgos que evidencian un carácter multifuncional: Chug-Chug 1, Aguada Chug-Chug y Abra Norte, los dos últimos asociados a geoglifos. A pesar de que Aguada Chug-Chug se relaciona con el abastecimiento de agua, no encontramos allí contextos de descanso, sino una gran cantidad de estructuras no habitacionales como líneas, amontonamientos de piedra y "sepulcros". Al igual que el anterior conjunto de sitios, la cerámica se encuentra asociada a challa de mineral de cobre $\mathrm{y}$, en algunos casos, a restos líticos, malacológicos $\mathrm{y}$ vegetales.

En Chug-Chug 1, dos estructuras colindantes óptimas para el descanso y resguardo presentan escasos fragmentos cerámicos junto a desechos líticos, pero la mayoría del material se registra sobre un amontonamiento de piedra challado con mineral de cobre.

El caso del sitio Abra Norte es más complejo, ya que hay gran cantidad de concentraciones de 
Tabla 5. Sitios arqueológicos y materiales asociados.

Archaeological sites and associated materials.

\begin{tabular}{|c|c|c|c|c|c|c|c|c|c|c|}
\hline $\begin{array}{l}\text { Geoglifos, estructuras } \\
\text { y materiales culturales }\end{array}$ & 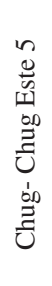 & 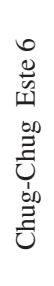 & 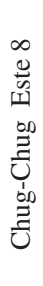 & 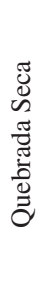 & 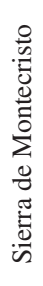 & 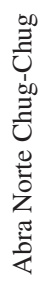 & 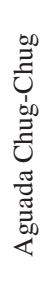 & 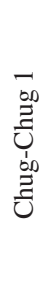 & 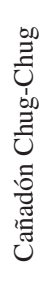 & 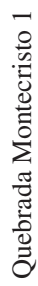 \\
\hline Geoglifos & $\mathrm{x}$ & & & & & $\mathrm{x}$ & $\mathrm{x}$ & & & \\
\hline Amontonamiento de piedras & $\mathrm{x}$ & $\mathrm{x}$ & $\mathrm{x}$ & $\mathrm{x}$ & $\mathrm{x}$ & $\mathrm{x}$ & $\mathrm{x}$ & & & \\
\hline Muros y cajas & $\mathrm{x}$ & & & & $\mathrm{x}$ & $\mathrm{x}$ & & & & \\
\hline Líneas de piedra & & & & & & $\mathrm{x}$ & $\mathrm{x}$ & & & \\
\hline Oquedades artificiales (sepulcros) & & & & $\mathrm{x}$ & & $\mathrm{x}$ & $\mathrm{x}$ & & & \\
\hline Depresiones o estructuras a ras de suelo & & $\mathrm{x}$ & $\mathrm{x}$ & $\mathrm{x}$ & & $\mathrm{x}$ & & $\mathrm{x}$ & & $\mathrm{x}$ \\
\hline Recintos pircados y parapetos & & & & & $\mathrm{x}$ & $\mathrm{x}$ & & $\mathrm{x}$ & & $\mathrm{x}$ \\
\hline Estructuras de señalización & & & & & & $\mathrm{x}$ & & & & \\
\hline Estructura de almacenaje o collca & & & & & & & & & $\mathrm{x}$ & \\
\hline Plaquitas de oro y plata & & & & & & $\mathrm{x}$ & & & & \\
\hline Figurilla femenina de piedra & & & & & & $\mathrm{x}$ & & & & \\
\hline Cuentas & & & $\mathrm{x}$ & $\mathrm{x}$ & $\mathrm{x}$ & $\mathrm{x}$ & & & & \\
\hline Pigmento rojo & & & & $\mathrm{x}$ & & & & & & \\
\hline Fósiles & & & & & & $\mathrm{x}$ & & & & \\
\hline Challa de mineral de cobre & $\mathrm{x}$ & $\mathrm{x}$ & $\mathrm{x}$ & $\mathrm{x}$ & $\mathrm{x}$ & $\mathrm{x}$ & $\mathrm{x}$ & $\mathrm{x}$ & & \\
\hline Malacológico & $\mathrm{x}$ & $\mathrm{x}$ & & $\mathrm{x}$ & $\mathrm{x}$ & & & & & \\
\hline Desechos líticos & $\mathrm{x}$ & & $\mathrm{x}$ & $\mathrm{x}$ & $\mathrm{x}$ & $\mathrm{x}$ & $\mathrm{x}$ & & & $\mathrm{x}$ \\
\hline Vegetales & & & $\mathrm{x}$ & $\mathrm{x}$ & $\mathrm{x}$ & $\mathrm{x}$ & & & & $\mathrm{x}$ \\
\hline Cordelería y restos de textil & & & & & & $\mathrm{x}$ & & & & \\
\hline Plumas y vellones & & & & & & $\mathrm{x}$ & & & & \\
\hline Osteofauna & & & & & & & $\mathrm{x}$ & & & $\mathrm{x}$ \\
\hline Osteofauna peces & & & & & & $\mathrm{x}$ & & & & \\
\hline Fecas & & & & & & $\mathrm{x}$ & & & & \\
\hline
\end{tabular}

cerámica en toda la superficie del sitio. Sin embargo, en su mayoría se relacionan espacialmente a sectores representados por algún tipo de estructura, geoglifos o la vía misma (Figura 2). El último es el caso más abundante, luego los primeros. Destacan los "sepulcros" de la estructura 35 -en ladera noreste a 10 metros de un geoglifo- y de las estructuras 23A a 23R, al costado sureste de la ruta. También son notorios los amontonamientos a ras de suelo -estructuras 4A y 4B- ubicados cercanos a los primeros "sepulcros" y un grupo de alineamientos de piedra ubicados en la misma ladera entre dos geoglifos. Otro sector que merece atención es un área cercana a la vía con importante evidencia de pigmento. No menos relevantes son las concentraciones cerámicas registradas en la ladera junto a "cajitas" y amontonamientos a ras de suelo en las cercanías de geoglifos (estructuras
58A y B, 59 y 60). En la mayoría de estos casos, la cerámica se registra junto a mineral de cobre y cuentas líticas, a excepción de las estructuras 23, donde los materiales son más variados (Tabla 5). Por último, resulta importante la estructura 1 o $\mathrm{ca}$ machico (sensu Pimentel 2012), la cual corresponde a un montículo de piedras con diversas ofrendas depositadas en sus intersticios y en pequeñas excavaciones probablemente hechas a mano antes de completarse su construcción (Figura 7). Además de cerámica, el sondeo permitió recuperar challa de mineral de cobre y hematita, plaquitas de oro y plata, abundantes instrumentos y desechos líticos, fósiles, una litoescultura fracturada que representa una mujer, cuentas de malaquita, crisocola y turquesa, chañar, algarrobo, maíz, vellones, cordelería, plumas, vidrio, fecas y huesos de pescado, entre otros (Blanco 2012; Rees et al. 2010). La cerámica 


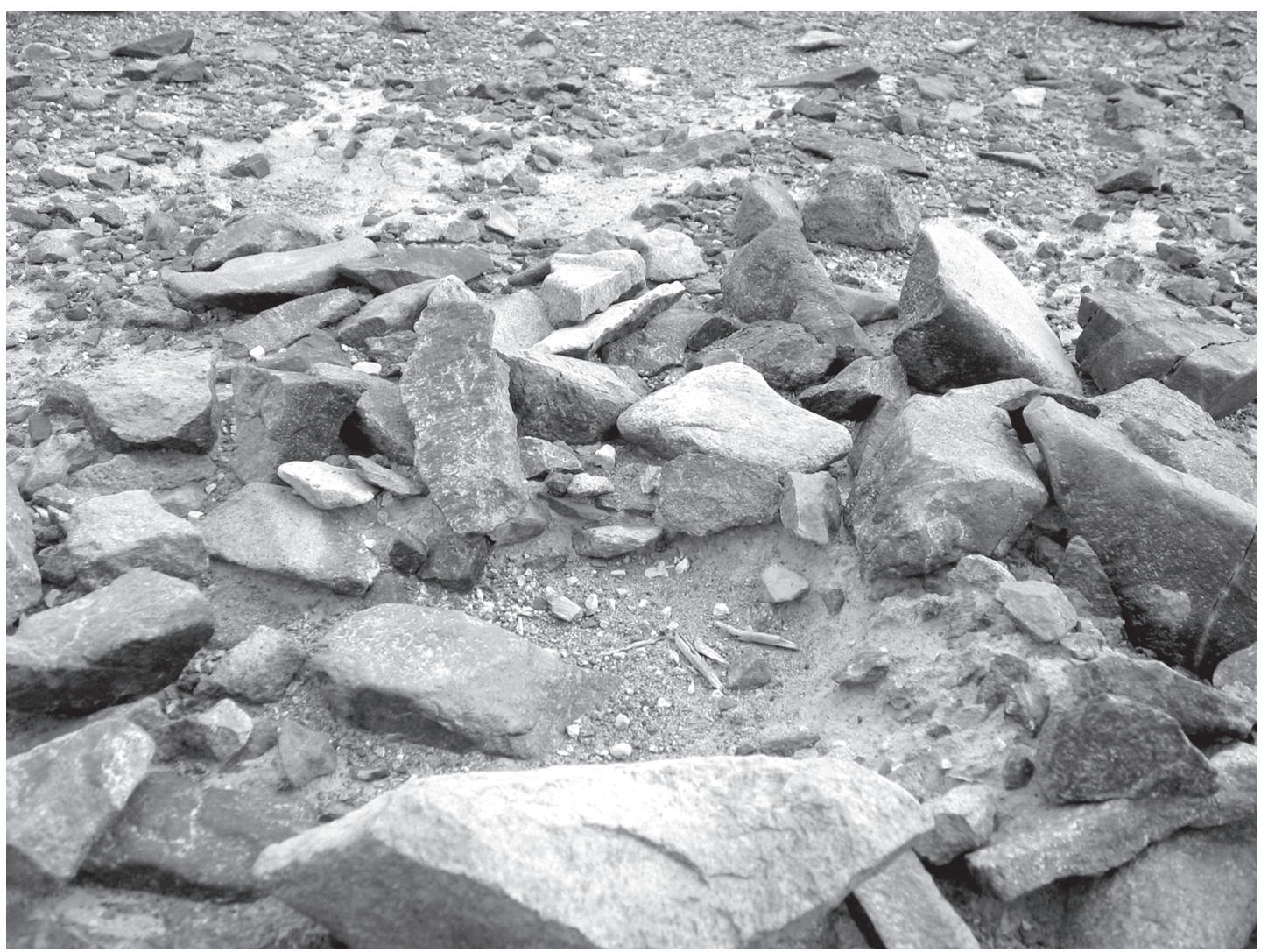

Figura 6. Ejemplo de "Sepulcro" y ofrendas asociadas, sitio Quebrada Seca. Foto: G. Pimentel.

Example of "sepulchre" and associated offerings, Quebrada Seca site. Photo: G. Pimentel.

registrada consiste mayoritariamente en fragmentos depositados de la misma manera que el resto de las ofrendas, incluida una olla cuya restaurabilidad sugiere que fue fracturada y ofrendada en las pequeñas excavaciones del costado de la estructura.

A pesar de que en Abra Norte existen estructuras que parecen ser de refugio o pernocte, la cerámica asociada a ellas es escasa, como sucede, por ejemplo, en la estructura 3, correspondiente a un muro semicircular en cuyas cercanías se registraron además desechos e instrumentos líticos y restos óseos. Las concentraciones cerámicas en asociación a la vía son abundantes, constituyendo el espacio desde donde son visibles los geoglifos (Figura 2), por lo que postulamos que su fractura no obedece solo a un accidente en el camino.

En la gran mayoría de los casos, la cerámica se registró a partir de conjuntos de fragmentos con alta restaurabilidad y asignables a vasijas únicas, sobre o junto a estructuras cuya morfología no ofrece refugio para el viaje. En estos contextos, la cerámica no se ve asociada a actividades de consumo y/o preparación de alimentos o a estructuras de combustión, sino más bien directamente relacionada con la challa de mineral de cobre, la que se reconoce ampliamente como el elemento más común del ceremonialismo del viajero en el mundo andino (Pimentel 2009). Lo anterior permite inferir que las vasijas fueron fracturadas también a modo de challa en directa relación a "cajitas", "sepulcros", amontonamientos de piedra, camachico y geoglifos.

En el único sitio donde la cerámica se relaciona con un contexto aparentemente habitacional es Quebrada Montecristo 1, con dos sectores diferenciados de estructuras que podrían no ser contemporáneos: uno, compuesto de depresiones subovales alineadas que nos recuerdan las llamadas paskanas y el otro, a unos $10 \mathrm{~m}$ del anterior, compuesto por recintos pircados de planta ortogonal. Se registraron fragmentos del período Intermedio Tardío (TRR, TRA, TGA, TRP y PCZ) en la superficie 

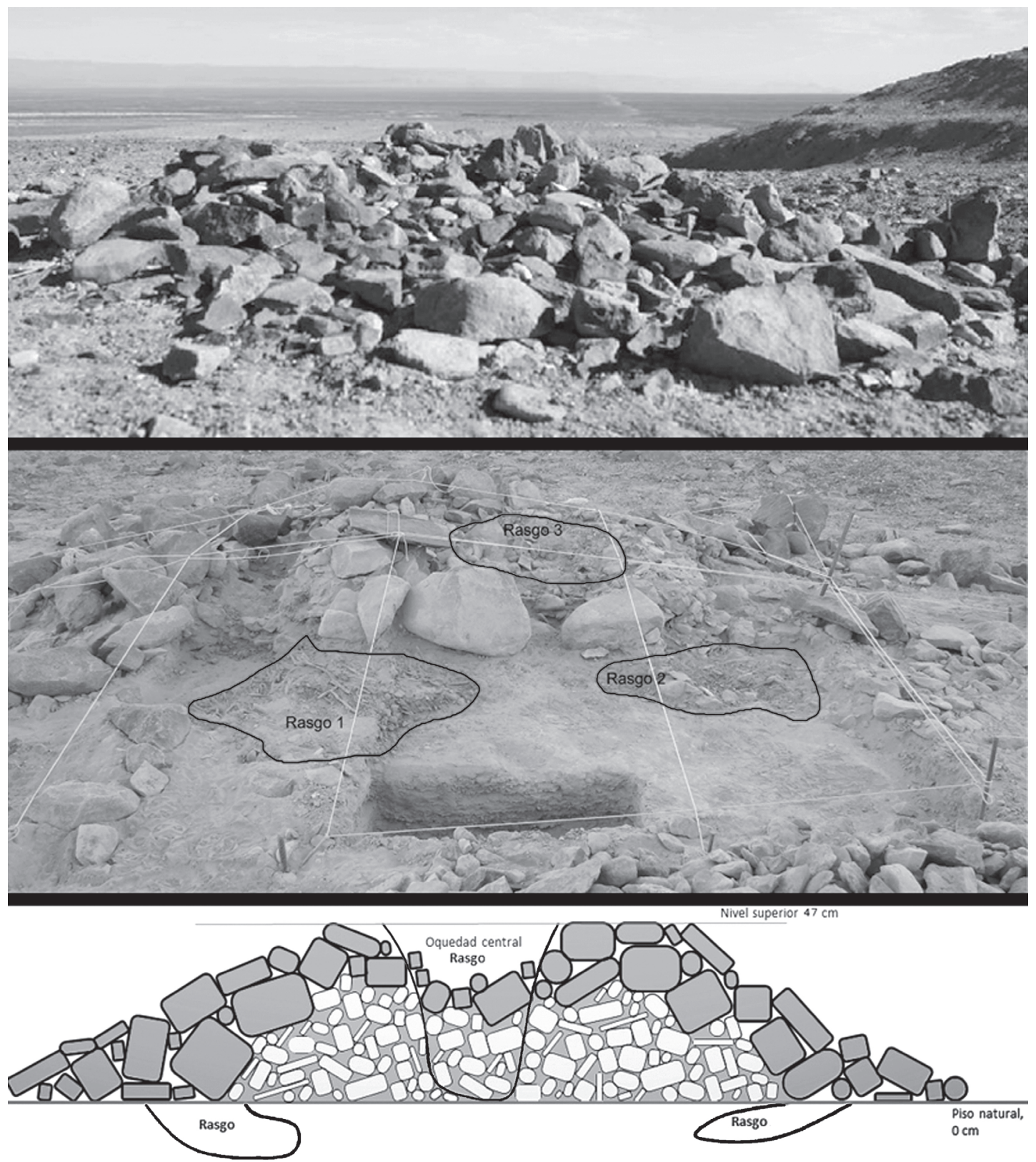

Figura 7. Vista general, excavación y corte transversal del Camachico, sitio Abra Norte. Modificado de Blanco 2012: figuras 3, 6 y 7. General view, excavation and schematic view of Camachico, Abra Norte site, Chug-Chug. Modified from Blanco 2012: figures 3,6 and 7 .

de ambos sectores, encontrándose también restos óseos, vegetales y líticos.

Por último, el sitio Cañadón Chug-Chug refiere a una estructura abovedada junto a la vía que puede ser vinculada al almacenaje (tipo collca), en la cual la única evidencia material fueron escasos restos de una pieza LCP.

\section{Cronología y Contextos}

Las ocupaciones alfareras iniciales de la ruta Chug-Chug se expresan en tipos cerámicos propios del Periodo Medio de Atacama (ca. 400-900 d.C.) y del Formativo Tardío de Tarapacá (ca. 0-900 d.C.). Los tipos SNP y QTC, correspondientes a una y 
otra tradición respectivamente, aparecen asociados tanto en los "sepulcros" de Quebrada Seca como en dos puntos cercanos a la vía en la superficie de Abra Norte, uno de ellos relacionado con el sector de pigmentos. En otros puntos de este último, SNP apareció aislado mientras que QTC se halló asociado a las líneas de piedra que se ubican entre dos geoglifos, uno de ellos con motivo antropomorfo propio del componente Tarapacá (cf. Pimentel y Montt 2008). De acuerdo con la literatura estos tipos son, hacia el año 500 d.C., las expresiones más comunes de sus respectivas tradiciones alfareras, no obstante, su asociación contextual no había sido antes documentada. En el oasis de Quillagua, por ejemplo, que hacia el Intermedio Tardío se constituye como un espacio de frontera y negociación entre ambas tradiciones, los contextos funerarios más tempranos nunca evidenciaron esta asociación (Agüero 1999, 2004; Uribe y Ayala 2004). Por otra parte, la asociación de los tipos anteriores con el tipo COY se registró sólo en la superficie de Abra Norte en el sector de pigmentos, pero no en los "sepulcros" de Sierra Montecristo, donde sólo se registró COY. Al mismo tiempo, todos los tipos mencionados se asocian a TRA, TRB y AIQ, hasta ahora documentados para tiempos posteriores, desde los inicios del Intermedio Tardío (Uribe 2002, 2004), dando cuenta de una reutilización de los espacios. Por su parte, QRP lo encontramos sólo en hallazgos aislados en dos puntos de la ruta: en los tramos Aguada/ChugChug 1 y Chug-Chug/Montecristo. Finalmente, es destacable la presencia de un fragmento TIW en la superficie de Abra Norte, a unos 10 metros de la estructura camachico.

Al mismo tiempo, los tipos Loa-San Pedro del Intermedio Tardío parecen utilizarse en todo tipo de contextos, y no sólo en los ceremoniales como es la tendencia más temprana de la misma tradición. Ello refuerza una idea ya planteada anteriormente, referida al cambio que se produce en los inicios del Intermedio Tardío, cuando comienzan a incorporarse vasijas domésticas a los espacios ceremoniales (Agüero et al. 1999; Uribe 2004).

Siguiendo con el análisis, los contextos cerámicos del Intermedio Tardío pueden segregarse en dos clases de patrones: uno, asociado a tipos locales (TRA, TRR, TRP, TGA Y AIQ), y otro, donde estos se combinan con los tipos altiplánicos y del NOA. El primer caso lo observamos en Quebrada Seca, que se mantendría en uso desde la época anterior, ChugChug 1, Aguada Chug-Chug, Chug-Chug Este 5,
Chug-Chug Este 8, geoglifos de Abra Norte además de otros puntos sobre la vía y aislados, y Quebrada Montecristo 1. Todos estos poseen un componente ceremonial destacable, excepto el último sitio de carácter más bien habitacional.

Tanto en Abra Norte como en Chug-Chug 1 y Quebrada Montecristo 1 se registró además alfarería del componente Tarapacá contemporánea a los tipos anteriores, fragmentos de botellas $\mathrm{PCH}$ y un modelado PCZ. Destaca la botella hallada en una estructura subcircular a ras de suelo del primer sitio (estructura 40), que fue restaurada a partir de la presencia de 156 fragmentos (Figura 4c). La vasija presenta un orificio acotado y subcircular en la sección inferior del cuerpo desde donde se orientan las líneas de fractura de la pieza, indicio de que esta fue quebrada intencionalmente o "matada".

Por último, los "sepulcros" de Abra Norte -estructuras 23A-R y 35- también reflejan este patrón, aunque cuentan con fragmentos YAV y TRN.

El patrón anterior puede ser comparable con otros contextos de la región, como el campamento minero Chu-2 (Núñez et al. 2003), el primer momento del pukara de Turi o Turi I (Uribe 2002; Varela 1992), los cementerios de Quillagua y Chacance (Agüero et al. 1999; Uribe y Ayala 2004; Uribe 2002), la aldea La Capilla (Cervellino y Téllez 1980) y la ruta que conectó Calama con Chuquicamata (Correa y García 2011). Todos ellos han sido datados en los inicios del Intermedio Tardío (fase Yaye, ca. 950-1.200 d.C.), en los cuales hay un protagonismo de las escudillas Ayquina y Dupont en asociación con tipos Turi y variantes y ausencia de tipos foráneos, que en cierto modo expresan una mayor circunscripción espacial en relación con lo que ocurrirá a partir del siglo XIII (fase Solor o Turi II, ca. 1.350-1.560 d.C.), cuando ingresan con mayor intensidad las cerámicas foráneas.

Los contextos que hemos relacionado con este segundo patrón y/o fase se encuentran representados en Abra Norte, en especial con la estructura camachico y geoglifos, Cañadón Chug-Chug, Chug-Chug Este 6 y Sierra Montecristo. En ellos, los tipos locales aparecen combinados con cerámicas del Altiplano Meridional (CHP, TAL), del Noroeste Argentino (YAV) y de tiempos incaicos (TRN, TPA, LCP, YAV La Paya e INK) y etnográficos (TCA). Un patrón similar ha sido registrado para el segundo momento del pukara de Turi o Turi II y en otros sitios de la cuenca del río Salado (Varela 1992; Uribe 2002).

En relación con lo anterior, en el camachico de Abra Norte, los tipos Loa-San Pedro muestran 
un alto grado de restaurabilidad, muy posiblemente quebrados in situ, mientras que las cerámicas foráneas corresponden más bien a fragmentos aislados. Asimismo, la ausencia de tipos de Tarapacá y la alta densidad de carozos de chañar, bastante escasos en los contextos de esta última región (Cf. García y Uribe 2011; García et al. 2014), así como la abundancia de challa de mineral de cobre y cuentas, permite plantear que el ceremonialismo asociado a la estructura se vincula al componente Loa-San Pedro de tiempos tardíos. Por su parte, sobre y muy cerca (8 a 20 m) de los geoglifos de Abra Norte, se registran principalmente vasijas fragmentadas de tradición Loa-San Pedro del Intermedio Tardío y Tardío (TRA, TRP, TRR, AIQ y TRN). Algo similar sucede con el sector de "sepulcros" ubicado al noroeste del sitio, con la excepción de escasos fragmentos Pica Charcollo y Yavi.

Finalmente, los sitios con cerámica de tiempos incaicos corresponden a Abra Norte, Sierra Montecristo y Cañadón Chug-Chug. Estos pueden ser comparados con los contextos de tránsito asociados al Qapaq Nan, como los estudiados en el tramo Miño-Lasana, donde las escudillas constituyen la categoría de vasija más representada, en especial las decoradas (TPA), seguido por los cántaros TRA y las ollas TGA (Uribe y Cabello 2005). La mayor frecuencia que alcanzan estas últimas es coherente con la presencia de actividades domésticas reiteradas en estos sitios.

\section{Conclusiones}

Los resultados obtenidos permiten señalar que el tránsito entre los oasis de Calama y Quillagua vía las quebradas de Chug-Chug y Montecristo se inició por lo menos a mediados del primer milenio de nuestra era, durante el Periodo Medio de Atacama o el Formativo Tardío de Tarapacá. Estas conexiones se intensificaron a partir del siglo $\mathrm{X}$, para luego decrecer y abandonarse en forma definitiva durante los inicios del periodo colonial. A lo largo de estos siglos, el componente Loa-San Pedro constituye la tradición alfarera preponderante, no obstante, hacia la segunda mitad del Intermedio Tardío se combina con otras tradiciones, principalmente de Tarapacá, seguida por el Noroeste Argentino y, finalmente, con componentes altiplánicos e incaicos.

A partir del comportamiento depositacional de la cerámica, podemos señalar que la alfarería Loa-San Pedro se distribuye en todas las clases de contextos de tránsito relevados. Un comportamiento similar posee la cerámica de Tarapacá, aunque teniendo en cuenta que sus frecuencias son mucho menores. Los tipos del Noroeste Argentino se asocian a los sitios ceremoniales siempre en relación con el componente Loa-San Pedro. Por su parte, los tipos del Altiplano Meridional (TAL y CHP) se registran en estructuras ceremoniales de Abra Norte, junto a TRA y TRP, y de Chug-Chug Este 6, sin asociación directa con otros tipos cerámicos. Por último, el tipo TIW se encuentra en Abra Norte junto a cerámicas del componente Loa-San Pedro aunque cercano al camachico, mientras que los dos fragmentos INK hallados en la muestra se asocian a este último.

Desde el punto de vista de las categorías de vasijas, los grandes contenedores restringidos (TRA, TRB y TRR), las botellas o aríbalos (TRN) y las escudillas (AIQ y TRP) constituyen las vasijas de mayor distribución, en toda clase de sitios. Ello indica que las vasijas movilizadas por Chug-Chug se adscriben funcionalmente al transporte, servicio y consumo de bebidas y alimentos, y poco a la preparación de estos, lo cual es coherente con la baja presencia de sitios habitacionales o de descanso. Por otra parte, el alto índice de fragmentos asignables a vasijas individuales, mayoritariamente del componente Loa-San Pedro, depositadas en estructuras y áreas ceremoniales en asociación a otros materiales, en especial challa de mineral de cobre, nos habla de su uso como ofrenda. En este sentido, hemos registrado su presencia en "sepulcros", líneas de piedra y geoglifos, en general con fractura intencional. Además, se registra la depositación de fragmentos únicos de tipos foráneos como TAL, CHP, Yavi La Paya e INK, en estructuras que presentan otras ofrendas y especialmente challa de mineral de cobre. Con ello, sostenemos que los viajeros pudieron transportar estos últimos fragmentos por su eficacia simbólica y no por su función como contenedores (cf. Amuedo 2010; Gell 1998).

Asimismo, la observación de las huellas de uso nos permite concluir que en gran medida, muchas vasijas ofrendadas en las estructuras ceremoniales tuvieron una historia de uso doméstico previo. Lo que junto a sus rasgos morfofuncionales, nos permite argumentar que la mayoría constituyeron bienes de consumo de los viajeros, en especial las escudillas de tamaño individual y los jarros, botellas y aríbalos de mediano tamaño. Esto no excluye que su movilización en la ruta permita 
también su uso como bienes de intercambio y que sus contenidos potenciales (p.ej., frutos de chañar, vainas de algarrobo, maíz, harinas, charqui, chuño) pudieran ser orientados a este mismo fin. De todos modos, la etnografía señala que el transporte para el intercambio de esta clase de productos se dio más bien en costales y talegas más que en contenedores cerámicos (Lecoq 1987; Nielsen 2000). Una situación diferente presentan las vasijas TRB, que por su gran tamaño y peso, podrían estar siendo transportadas vacías y, a diferencia de las demás vasijas, podrían constituir bienes de intercambio sin retorno a su lugar de origen, lo que podría aplicar también a algunos contenedores TRA y TRR de mayor tamaño. En este sentido, debemos considerar que la jornada diaria de las llamas es de cerca de tres a cuatro leguas, es decir, 12 a $25 \mathrm{~km}$ (Lecoq 1987, 1998), con lo cual calculamos un mínimo de 4 a 5 jornadas de camino para efectuar el recorrido completo de la ruta de $110 \mathrm{~km}$.

Retomando la idea de las trayectorias de vida de los objetos, Appadurai (1991 [1986]) señala que en el contexto del intercambio, los objetos pueden ser producidos para tales fines o ser desviados a tal función en determinado momento de su vida. En este intercambio, plantea, se incluyen el trueque y el mercadeo, pero aquí reconocemos también la negociación necesaria de los viajeros con las entidades que habitan en el paisaje (p.ej., pachamama, cerros, "el tío", etc.), las cuales se hacen presentes a lo largo de los recorridos y son, en definitiva, responsables del éxito de los viajes. Por tanto, consideramos que las vasijas que fueron ofrendadas en los contextos ceremoniales de la ruta Chug-Chug pueden ser entendidas bajo esta perspectiva como objetos de consumo cotidiano que luego fueron usados en el marco de un intercambio simbólico con el fin de agradecer, rogar protección, aplacar o negociar, tal como ha sido referido en múltiples trabajos etnográficos (Castro 2002, 2009; Cruz 2006; Lecoq 1987; Martínez 1976). En esta línea destacamos, entre otras, dos vasijas que atestiguan este cambio en sus trayectorias de vida a partir de su inutilización intencional, expresando de este modo la agencia que puede alcanzar esta clase de objetos en los contextos ceremoniales estudiados. La primera se refiere a múltiples fragmentos TGA de una misma pieza, depositados al interior del camachico de Abra Norte. La segunda corresponde a una botella $\mathrm{PCH}$, reconstruida casi en totalidad, proveniente de una estructura subcircular a ras de suelo del mismo sitio, la que evidencia haber sido "matada".

La etnografía ofrece importantes antecedentes sobre el ceremonialismo en el que se encuentran inmersos los viajes con caravanas de llamas. Lecoq (1987) documenta ritos de inicio y fin de la travesía, así como ofrendas cotidianas para honrar a "los espíritus" durante la primera y última comida de cada día de viaje, consistentes en alimentos y coca. Consideramos muy sugerente la relación entre ceremonias, ofrendas y comidas diarias, ya que las vasijas cerámicas claramente participan de las actividades de consumo de alimentos y líquidos, relacionándose la subsistencia con el ámbito ritual. Por otra parte, algunas botellas y/o aríbalos son de importancia en la ritualidad andina, relacionadas con el transporte y consumo de bebidas alcohólicas (p.ej., chicha de maíz, chicha de algarrobo o aloja) y el uso de escudillas debió ser relevante para "servir" en el marco del ofertorio.

Finalmente, es posible entender el ceremonialismo de la ruta Calama-Quillagua tanto como una expresión simbólica de las fuertes exigencias físicas que implicó atravesar el desierto absoluto (Pimentel 2009, 2012), como también un campo de acción donde se proyectan identidades sociales en el espacio de tránsito. Lo anterior se sustenta en el hecho de que si bien los motivos representados en los geoglifos de Chug-Chug se plantean como la extensión sur de una expresión que hasta ahora se ha relacionado más bien con el componente Tarapacá (Pimentel y Montt 2008), identificamos un contrapeso expresado en la depositación asociada a mineral de cobre triturado, de abundante alfarería del componente Loa-San Pedro en los espacios relacionados con estos geoglifos, al menos desde el período Intermedio Tardío.

Agradecimientos: La coautora de este artículo es becaria Conicyt. Agradecemos al proyecto FONDECYT 1090762 a cargo de Gonzalo Pimentel por acoger esta propuesta. A Mauricio Uribe por su valiosa contribución en la identificación de los tipos cerámicos. A José Francisco Blanco por su apoyo en el análisis espacial de Abra Norte, la creación de muestrarios cerámicos y la reconstrucción de las piezas. A Mariana Ugarte por la elaboración de la Figura 1. A los evaluadores anónimos que permitieron mejorar sustancialmente este manuscrito. 


\section{Referencias Citadas}

Agüero, C., P. Ayala, M. Uribe, C. Carrasco y B. Cases 2004. El Periodo Formativo desde Quillagua, Loa Inferior (Norte de Chile). En Esferas de Interacción Prehistóricas y Fronteras Nacionales Modernas: los Andes del Sur Centrales, compilado por H. Lechtman, pp. 73-120. Institute of Andean Research, Actas del Taller Andino Internacional, Purmamarca.

Agüero, C., M. Uribe, P. Ayala y B. Cases 1999. Una aproximación arqueológica a la etnicidad y el rol de los textiles en la construcción de la identidad cultural en los cementerios de Quillagua (II región, Chile). Gaceta Arqueológica Andina 25:167-198.

Amuedo, C. 2010. La Muerte de Niños y su Tejido de Materialidad. Prácticas, Representaciones y Categorías Construidas en las Tumbas de Infantes en Vasijas, Período Tardío (900-1470 DC), Valle Calchaquí Norte. Tesis de Licenciatura, Facultad de Filosofía y Letras, Universidad de Buenos Aires, Buenos Aires.

Angelo, D. 2006. Líneas de tiempo y círculos de consumo: acerca de las relaciones de interacción en el altiplano sur andino. En Esferas de Interacción Prehistóricas y Fronteras Nacionales Modernas: los Andes Sur Centrales, editado por H. Lechtman, pp. 127-166. IEP y IAR, Lima.

Appadurai, A. 1991 [1986]. Introducción. Las mercancías y la política del valor. En La Vida Social de las Cosas, editado por A. Appadurai e I. Kopytoff, pp. 17-87. Editorial Grijalbo, México.

Ayala, P. 2001. Las sociedades formativas del altiplano circumtiticaca y meridional y su relación con el Norte Grande de Chile. Estudios Atacameños 21:7-40.

Berenguer, J. 2004. Caravanas, Interacción y Cambio en el Desierto de Atacama. Sirawi Ediciones, Santiago.

Blanco, J.F. 2012. El Componente Lítico de la Estructura 1 de Abra Norte de Chug-Chug, "Camachico". Informe de Práctica Profesional, Departamento de Antropología, Universidad de Chile, Santiago.

Bray, T. 2003. Inka pottery as culinary equipment: Food, feasting, and gender in imperial state design. Latin American Antiquity 14:3-28.

Briones, L. y C. Castellón 2005. Catastro de Geoglifos. Provincia de Tocopilla, Región de Antofagasta. Fondo de Desarrollo de la Cultura y las Artes, Consejo Nacional de la Cultura y las Artes, Tocopilla.

Briones, L., L. Núñez y V. Standen 2005. Geoglifos y tráfico prehispánico de caravanas de llamas en el desierto de Atacama (norte de Chile). Chungara Revista de Antropología Chilena 37:195-223.

Cases, B., C. Rees, G. Pimentel, R. Labarca y D. Leiva 2008. Sugerencias de un contexto funerario en un "espacio vacío" del desierto de Atacama. Boletín del Museo Chileno de Arte Precolombino 13:51-70.

Castro, V. 2002. Ayquina y Toconce: paisajes culturales del norte árido de Chile. En Paisajes Culturales en los Andes, pp. 209-222. Representación de la UNESCO en Perú, Lima.

- - - 2009. De Ídolos a Santos. Evangelización y Religión Andina en los Andes del Sur. Colección de Antropología, DIBAM, Santiago.
Cervellino, M. y F. Téllez 1980. Emergencia y desarrollo de una aldea prehispánica en Quillagua-Antofagasta. Contribución Arqueológica $\mathrm{N}^{\circ} 1$, Copiapó.

Correa, I. y M. García 2011. Vasijas prehispánicas movilizadas por la ruta Calama-Chuquicamata (MMH 10). Informe de análisis cerámico proyecto Mina Ministro Hales (MMH), Codelco VCP.

Cruz, P. 2006. Mundos permeables y espacios peligrosos. Consideraciones acerca de los punkus y qaqas en el paisaje altoandino de Potosí, Bolivia. Boletín del Museo Chileno de Arte Precolombino 11:35-50.

Eerkens, J. 2004. Privatization, small-seed intensification, and the origins of pottery in the Western Great Basin. American Antiquity 69:653-670.

García, M. y M. Uribe 2011. Contextos de uso de las plantas vinculadas al Complejo Pica Tarapacá, Andes Centro Sur: arqueobotánica y agricultura en el período Intermedio Tardío (ca. 1.250-1.450 d.C.). Estudios Atacameños 44:107-122.

García, M., A. Vidal, V. Mandakovic, A. Maldonado, M.P. Peña y E. Belmonte 2014. Alimentos, tecnologías vegetales y paleoambiente en las aldeas de la pampa del Tamarugal: dos expresiones del periodo Formativo en Tarapacá (ca. 900 a.C.-800 d.C.). Estudios Atacameños 47, en prensa.

Gell, A. 1998. Art and Agency. An Anthropological Theory. Clarendon Press, Oxford.

Henrickson E. y M. McDonald 1983. Ceramic form and function: An ethnographic search and an archaeological application. American Anthropologist 85:630-643.

Lazzari, M. 2005. The texture of the things: objects, people and landscape in Northwestern Argentina (First millenium A.D.). En Archaeologies of Materiality, editado por L. Meskell, pp. 126161. Blackwell, Oxford.

Lecoq, P. 1987. Caravanes de Lamas, Sel et Échanges Dans une Communauté de Potosí, en Bolivie. Boletín del Instituto Francés de Estudios Andinos 16:1-38.

- - - 1998. Algunos apuntes sobre el papel de los llameros y de las recuas de llamas en el auge de la Villa Imperial de Potosí. Cuadernos de Arquitectura y Geografía № 11, Facultad de Humanidades y Ciencias Sociales, Universidad Nacional de Jujuy.

Llagostera, A., M. Torres y M.A. Costa 1988. El complejo psicotrópico en Solcor-3 (San Pedro de Atacama). Estudios Atacameños 9:67-106.

Martínez, G. 1976. El sistema de los Uywiris en Isluga. Anales de la Universidad del Norte 10 (Homenaje al Dr. Gustavo Le Paige) pp. 255-327.

Martínez, J.L. 1998. Pueblos del Chañar y el Algarrobo: Los Atacamas en el Siglo XVII. DIBAM, Santiago.

Moragas, C. 1995. Desarrollo de las comunidades prehispánicas del litoral de Iquique-desembocadura río Loa. Actas XIII Congreso Nacional de Arqueología Chilena. Hombre y Desierto 9, Tomo I:65-83.

Munizaga, C. 1963. Tipos cerámicos del sitio Coyo en la región de San Pedro de Atacama. Actas del Congreso Internacional de 
Arqueología de San Pedro de Atacama. Anales de la Universidad del Norte 2:99-131.

Murra, J. 1975 [1972]. El "control vertical” en un máximo de pisos ecológicos en la economía de las sociedades andinas. En Formaciones Políticas y Económicas del Mundo Andino, pp. 59116, editado por J. Murra. Instituto de Estudios Peruanos, Lima.

- - - 1976. Los límites y la limitaciones del "archipiélago vertical" en los Andes. En Homenaje al Dr. Gustavo Le Paige, S.J., editado por H. Niemeyer, pp. 141-146. Universidad del Norte, Antofagasta.

Nielsen, A. 1997. El tráfico caravanero visto desde la jara. Estudios Atacameños 14:339-371.

- - - 2000. Andean Caravans: An Ethnoarchaeology. Tesis Doctoral en Arqueología, Departamento de Antropología, Universidad de Arizona, Tucson.

- - - 2006. Estudios internodales e interacción interregional en los Andes circumpuneños. En Esferas de Interacción Prehistóricas y Fronteras Nacionales Modernas: los Andes Sur Centrales, editado por H. Lechtman, pp. 29-62. IEP-IAR, Lima.

- - - 2011. El tráfico de caravanas entre Lípez y Atacama visto desde la Cordillera Occidental. En En Ruta. Arqueología, Historia y Etnografía del Tráfico Surandino, editado por L. Núñez y A. Nielsen, pp. 83-110. Editorial Brujas, Córdoba.

Núñez, L. 1965. Prospección arqueológica al Norte de Chile. Estudios Arqueológicos 1:9-36.

- - - 1976. Geoglifos y tráfico de caravanas en el Desierto chileno. En Homenaje al Dr. Gustavo Le Paige, S.J., editado por H. Niemeyer, pp. 147-201. Universidad del Norte, Antofagasta.

Núñez, L., C. Agüero, B. Cases y P. de Souza 2003. El campamento minero Chuquicamata-2 y la exploración cuprífera prehispánica en el desierto de Atacama. Estudios Atacameños 25:7-34

Núñez, L. y A. Nielsen 2011. Caminante, sí hay camino: reflexiones sobre el tráfico sur andino, En En Ruta. Arqueología, Historia y Etnografía del Trafico Surandino, editado por L. Núñez y A. Nielsen, pp. 83-110. Encuentro Grupo Editor, Córdoba.

Núñez, L. y T. Dillehay 1979 [1995]. Movilidad Giratoria, Armonía Social y Desarrollo en los Andes Meridionales: Patrones de Tráfico e Interacción Económica. Universidad Católica del Norte, Antofagasta.

Pimentel, G. 2009. Huacas del tráfico. Arquitectura ceremonial en rutas prehispánicas del desierto de Atacama. Boletín del Museo Chileno de Arte Precolombino 14:9-38.

- - - 2011a. Geoglifos e imaginarios sociales en el desierto de Atacama (región de Antofagasta, Chile). En Temporalidad, Interacción y Dinamismo Cultural. La Búsqueda del Hombre. Homenaje al Profesor Dr. Lautaro Núñez A., editado por A. Hubert, J.A. González y M. Pereira, pp. 163-200. Universidad Católica del Norte, Ediciones Universitarias, Antofagasta.

- - - 2011b. Estrategias de movilidad en ejes viales preincaicos que conectaron el Loa medio y la costa de la II región. Fondecyt 1090762, Informe año 2.

- - - 2012. Redes Viales Prehispánicas en el Desierto de Atacama. Viajeros, Movilidad e Intercambio. Tesis para optar al grado de Doctor en Antropología, Mención Arqueología, Universidad Católica del Norte-Universidad de Tarapacá, San Pedro de Atacama-Arica.
Pimentel, G. e I. Montt 2008. Tarapacá en Atacama. Arte rupestre y relaciones intersocietales entre el 900 y el 1450 d.C. Boletín del Museo Chileno de Arte Precolombino 13:35-50.

Pimentel, G., I. Montt, J. Blanco y A. Reyes 2007. Infraestructura y prácticas de movilidad en una ruta que conectó el Altiplano Boliviano con San Pedro de Atacama (II Región, Chile). En Producción y Circulación Prehispánica de Bienes en el Sur Andino, compilado por A. Nielsen, M.C. Rivolta, V. Seldes, M.M. Vásquez, P.H. Mercolli, pp. 351-382. Editorial Brujas, Córdoba.

Pimentel, G., C. Rees, P. de Souza y P. Ayala 2010. Estrategias de movilidad del período formativo en la depresión intermedia, desierto de Atacama. Actas del XVII Congreso Nacional de Arqueología Chilena, pp. 1353-1364. Ediciones Kultrún, Valdivia.

Pimentel, G., C. Rees, P. de Souza y L. Arancibia 2011. Viajeros costeros y caravaneros. Dos estrategias de movilidad en el Período Formativo del Desierto de Atacama, Chile. En En Ruta. Arqueología, Historia y Etnografía del Tráfico Surandino, editado por L. Núñez y A. Nielsen, pp. 43-81. Encuentro Grupo Editor, Córdoba.

Rees, C. 2011. Informe de excavación ChugChug. Fondecyt 1090762, Informe año 2.

Rice, P.M. 1987. Pottery Analysis: A Sourcebook. University of Chicago Press, Chicago.

Rye, O.S. 1981. Pottery Technology. Editorial Taraxacum, Washington.

Sanhueza, J. y O. Olmos 1981. Usamaya 1, cementerio indígena de Isluga, Altiplano de Iquique, I Región, Chile. Chungara 8:169-207.

Shepard, A. 1985 [1956]. Ceramics for the Archaeologist. Carnegie Institute of Whashington, Washington, D.C.

Salomon, F. 1985. The dynamic potential of the complementarity concept. En Andean Ecology and Civilization. An Interpretative Perspective on Andean Ecological Complementarity, editado por S. Mashuda, I. Shimada y C. Morris, pp. 511-531. University of Tokio Press, Tokio.

Tarragó, M. 1989. Contribución al Conocimiento Arqueológico de las Poblaciones de los Oasis de San Pedro de Atacama en Relación con los Otros Pueblos Puneños, en Especial del Sector Septentrional del Valle Calchaquí. Tesis de Doctorado en Historia, Especialidad Arqueología, Universidad Nacional de Rosario, Rosario.

Uribe, M. 2002. Sobre alfarería, cementerios, fases y procesos durante la prehistoria tardía del desierto de Atacama (8001600 DC). Estudios Atacameños 22:7-31.

- - - 2004. Alfarería, Arqueología y Metodología. Aportes y Proyecciones de los Estudios Cerámicos del Norte Grande de Chile. Tesis para optar al grado de Magíster en Arqueología. Departamento de Antropología, Universidad de Chile, Santiago.

- - - 2006. Acerca de complejidad, desigualdad social y el complejo cultural Pica-Tarapacá en los Andes Centro-Sur (10001450 DC). Estudios Atacameños 31:91-114.

Uribe M. y P. Ayala 2004. La alfarería de Quillagua en el contexto formativo del Norte Grande de Chile (1000 a.C.-500 d.C.) Chungara Revista de Antropología Chilena, Volumen Especial, Tomo 2, pp. 585-597. 
Uribe, M. y G. Cabello 2005. Cerámica en el camino: los materiales del río Loa (Norte Grande de Chile) y sus implicaciones tipológicas y conductuales para la comprensión de la vialidad y la expansión del Tawantinsuyo. Revista Española de Antropología Americana 35:75-98.

Uribe, M., L. Sanhueza y F. Bahamondes 2007. La cerámica Prehispánica Tardía de Tarapacá, sus valles interiores y costa desértica, Norte de Chile (CA. 900-1450 d.C.): Una propuesta tipológica y cronológica. Chungara Revista de Antropología Chilena 39:143-170.

Van Buren, M. 1996. Rethinking the Vertical Archipelago. Ethnicity, exchange, and history in the South Central Andes. American Anthropologist 98:338-351.

Varela, V. 1992. De Toconce Pueblo de Alfareros, a Turi Pueblo de Gentiles. Memoria de Título en Arqueología. Departamento de Antropología, Universidad de Chile, Santiago. 